\title{
Impact of agricultural-based biofuel production on greenhouse gas emissions from land-use change: Key modelling choices
}

\author{
Luis Panichelli*,1, Edgard Gnansounou \\ Bioenergy and Energy Planning Research Group (GR-GN - INTER - ENAC), Ecole Polytechnique Fédérale de Lausanne (EPFL), Station 18, \\ CH-1015 Lausanne, Switzerland
}

\section{A R T I C L E I N F O}

\section{Article history:}

Received 23 March 2014

Received in revised form

25 August 2014

Accepted 12 October 2014

\section{Keywords:}

Biofuel

Land-use change

Greenhouse gas emission

Modelling choice

Policy

\begin{abstract}
A B S T R A C T
Recent regulations on biofuels require reporting of greenhouse gas (GHG) emission reductions related to feedstock-specific biofuels. However, the inclusion of GHG emissions from land-use change (LUC) into law and policy remains a subject of active discussion, with LUC-GHG emissions an issue of intense research. This article identifies key modelling choices for assessing the impact of biofuel production on LUC-GHG emissions. The identification of these modelling choices derives from evaluation and critical comparison of models from commonly accepted biofuels-LUC-GHG modelling approaches. The selection and comparison of models were intended to cover factors related to production of agricultural-based biofuel, provision of land for feedstock, and GHG emissions from land-use conversion. However, some fundamental modelling issues are common to all stages of assessment and require resolution, including choice of scale and spatial coverage, approach to accounting for time, and level of aggregation. It is argued here that significant improvements have been made to address LUC-GHG emissions from biofuels. Several models have been created, adapted, coupled, and integrated, but room for improvement remains in representing LUC-GHG emissions from specific biofuel production pathways, as follows: more detailed and integrated modelling of biofuel supply chains; more complete modelling of policy frameworks, accounting for forest dynamics and other drivers of LUC; more heterogeneous modelling of spatial patterns of LUC and associated GHG emissions; and clearer procedures for accounting for the time-dependency of variables. It is concluded that coupling the results of different models is a convenient strategy for addressing effects with different time and space scales. In contrast, model integration requires unified scales and time approaches to provide generalised representations of the system. Guidelines for estimating and reporting LUC-GHG emissions are required to help modellers to define the most suitable approaches and policy makers to better understand the complex impacts of agricultural-based biofuel production.
\end{abstract}

(c) 2014 Elsevier Ltd. All rights reserved.

\section{Contents}

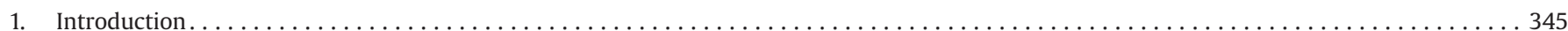

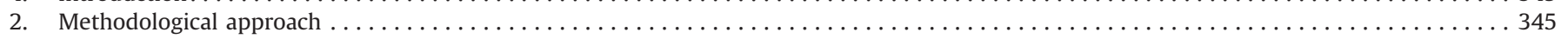

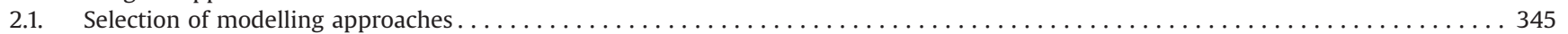

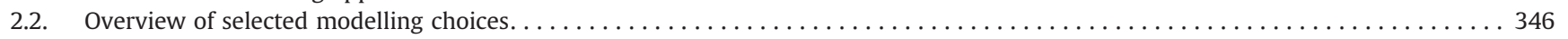

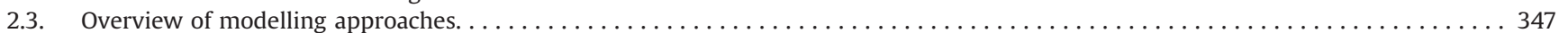

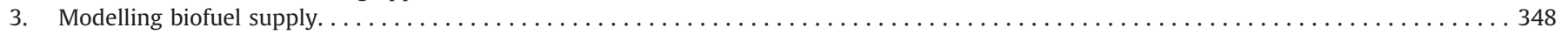

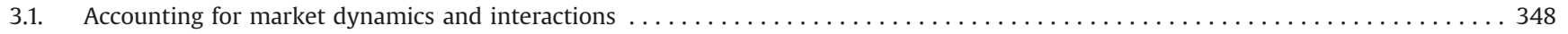

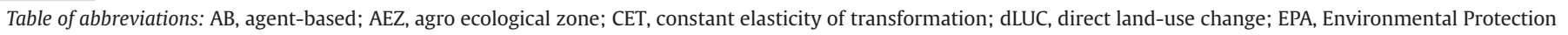

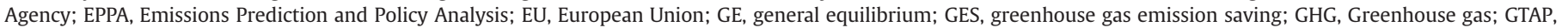

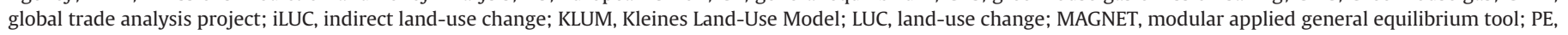

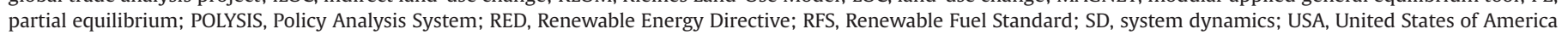

* Corresponding author. Tel.: + 33745971365.

E-mail address: lpanichelli@gmail.com (L. Panichelli).

${ }^{1}$ Present address: Rr. Pjeter Bogdani 13, Prishtina 10000, Kosovo. 


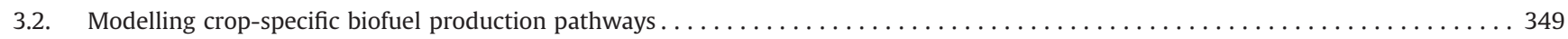

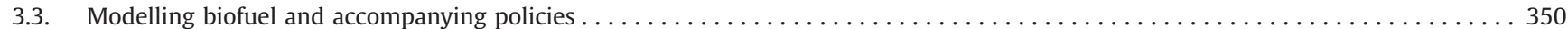

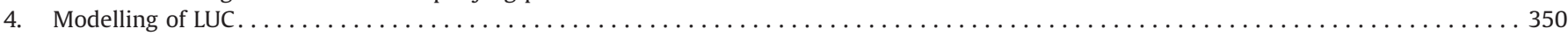

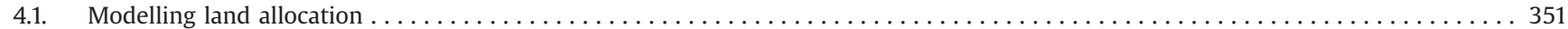

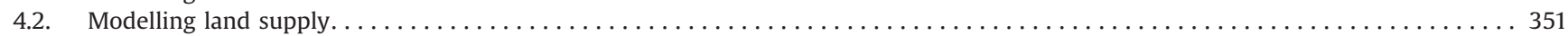

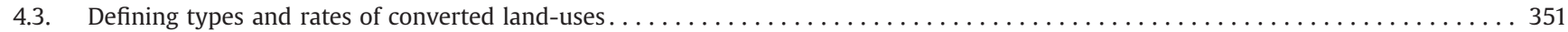

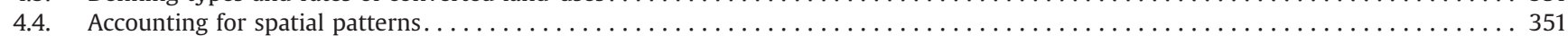

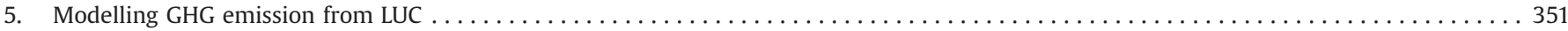

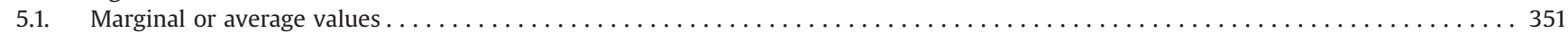

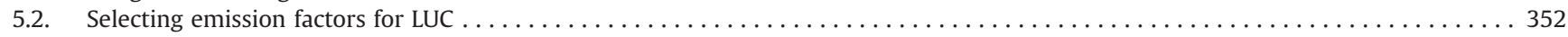

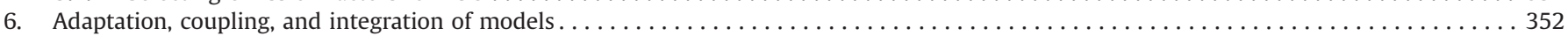

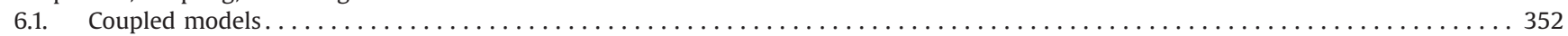

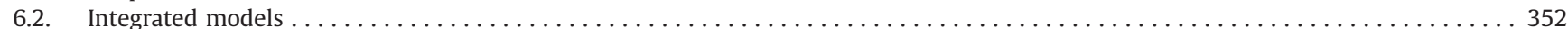

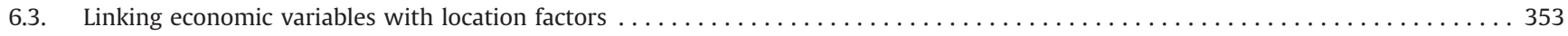

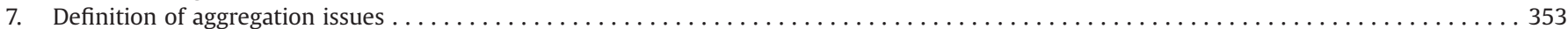

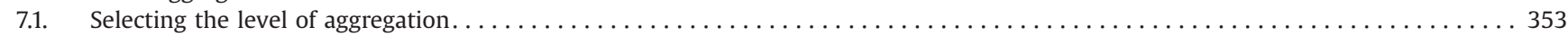

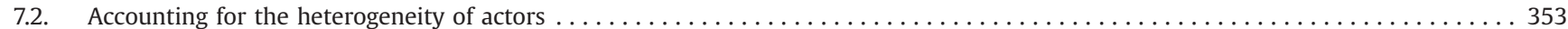

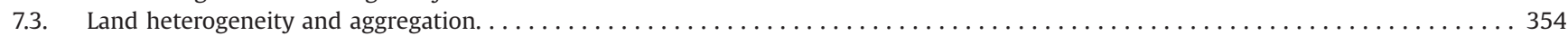

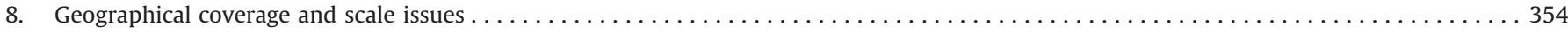

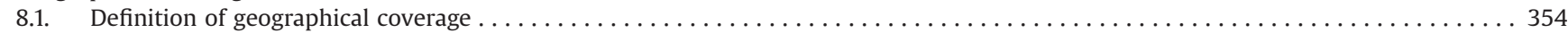

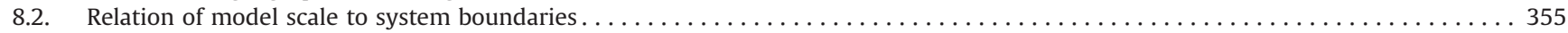

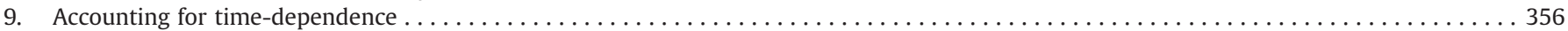

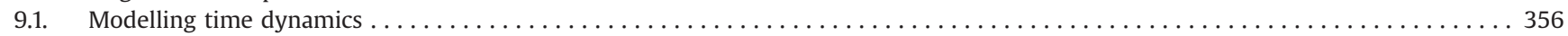

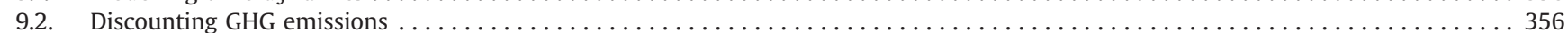

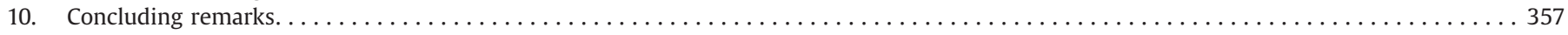

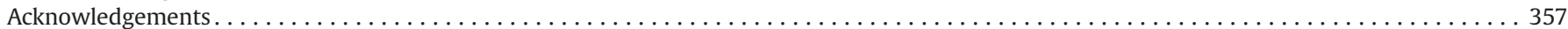

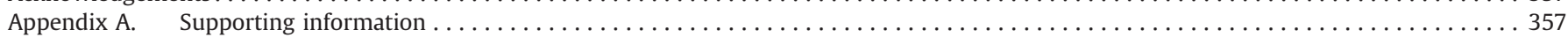

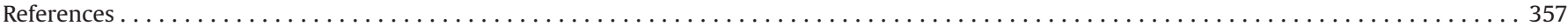

\section{Introduction}

Concerns about biofuel sustainability have pushed governments and international agencies to develop sustainability criteria for biofuels that producers must respect [1]. Special attention has been given to reporting the greenhouse gas (GHG) emission savings (GES) of biofuels [2]. Several countries have issued regulations that require reporting the GHG emission performance of biofuels. These regulatory schemes include the Renewable Transport Fuel Obligation in the United Kingdom (UK), the Renewable Energy Directive (RED) in the European Union (EU), the Low-carbon Fuel Standard in the State of California, and the Environmental Protection Agency's (EPA) Renewable Fuel Standard (RFS) in the United States of America (USA) [3-5].

A major point of discussion in the assessment of biofuel GES is the impact of feedstock production on land-use change (LUC) [6,7]. In the case of agricultural-based feedstock for biofuels, recent studies point to the significance of LUC-GHG emissions for the overall GHG emission balance of biofuels [2,8-14]. When LUC occurs, the GES of biofuels may be offset by the direct or indirect contribution to carbon stock changes in land [15]. Consequently, in recent years, the number of studies dealing with biofuels, LUC, and GHG emissions has grown sharply [16].

Quantitative estimates of LUC-GHG emissions vary significantly because of the variety of biofuel production pathways being considered and the complexity of the system being addressed [17]. The current lack of reliable and unified methodologies and consistent data to perform the estimate has caused governments to become cautious when considering inclusion in biofuel standards and policy [18]. This combination of factors may have contributed to the considerable variation in regulatory schemes that address LUCGHG emissions. Possibly as a response to this uncertainty, estimation of LUC-GHG emissions from the production of feedstock for biofuels has become a significant focus of research while debate on policy inclusion continues [19-21].

The literature on these issues is vast and not well crossreferenced, opening the possibility that modellers will be unaware of related work in complementary fields. Indeed, reviews of LUCGHG emissions from biofuel production have focused mainly on the comparison of global economic approaches and their simulation results [17].

This paper provides a broader assessment of commonly used modelling approaches. Through comparison of models, two key features are identified: (1) important modelling parameters for assessing LUC-GHG emissions from biofuels, and (2) the adequacy of each modelling approach in the assessment of nexus issues in the fields of biofuels, LUC, and GHG emissions. Also provided is comment on the limitations of common modelling approaches, with exploration and discussion of possibilities for improvement.

\section{Methodological approach}

\subsection{Selection of modelling approaches}

This review of modelling approaches highlights conceptual aspects of the different modelling procedures; results of simulation approaches are not reported or discussed. Other authors have acknowledged the diversity of model-based results and the uncertainty linked to the estimation $[7,17,19,22]$, and the current review is not needed as a contribution to that work. For this paper, the main factors influencing the measurement of LUC-GHG emissions from biofuel production have been studied, and previous reviews on the subject have been analysed, leading to the conclusion that a broader assessment of modelling approaches is needed to overcome current limitations.

Measuring LUC-GHG emissions from biofuel production is a major issue for two specific needs: the inclusion of the estimation in government regulations, and the certification of sustainable biofuels at the producer level. Three methodologies have been applied to measure LUC-GHG emissions caused by feedstock production of biofuels: empirical observations, causal-descriptive assessments, and modelling and simulation (Fig. 1). 
The modeller should consider the type of LUC being addressed when selecting modelling approaches. These types include direct LUC (dLUC), defined as the direct expansion of biofuel feedstock into other types of land-uses, and indirect LUC (iLUC), defined as the first-grade expansion of the displaced land-uses into other types of land-uses.

Although empirical methods have been used mainly to trace historical dLUC and assign emissions to particular biofuel producers, modelling and simulation have focused more on projecting LUC from biofuel policies [23]. Producers have targeted measuring local dLUC induced by each batch of biofuel produced; however, governments generally support the inclusion of dLUC estimations in policy while suggesting the monitoring of iLUC at the country and international levels.

Empirical observations are applied by the biofuels industry primarily for certification purposes. Implementation and monitoring occur using historical time-series and satellite images to identify historical LUCs where biofuels are being produced [24]. In contrast, modelling and simulation have been the primary tools used at the government level in support of policy analysis. As noted, the uncertainty associated with the modelling estimates of LUC-GHG emissions has caused a shift towards a more deterministic approach and away from the difficult task of estimating

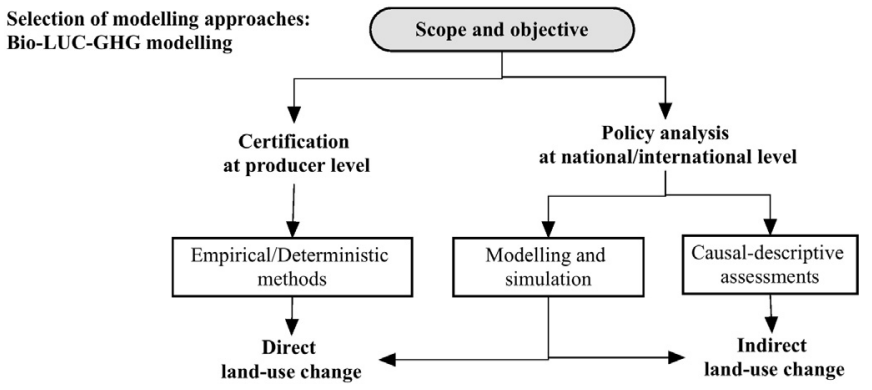

Fig. 1. Selection of modeling approaches by scope and objective. values based upon uncertain modelling. However, the problem of data quality and availability persists.

Causal-descriptive methods rely on simple analyses of historical data and expert opinions about system composition and dynamics. Although they are useful for understanding the macro-picture of LUC induced by biofuel production and to identify urgent areas for further analyses, they do not provide a basis for narrowly tailored policy-making or contribute to policy makers' efforts to include dLUC in biofuel GHG emission balance.

The discussion in this paper targets technical approaches to supporting policy-making. Accordingly, empirical and causaldescriptive methods are excluded, allowing a focus on the specificities of modelling approaches used to tackle different aspects of the links among biofuel production, LUC, and GHG emissions.

Following the modelling assessment, a web-based literature review was conducted to identify and select publications addressing these issues. Each chosen publication contains a modelling framework that can include one or several models. A general assessment of the overall collection of models was then used to evaluate the current state of the art in the model-based estimation of LUC-GHG emissions from biofuel production. Furthermore, several models were included as relevant primarily because they provide insight into unexplored issues and help to overcome current limitations.

\subsection{Overview of selected modelling choices}

From a modelling perspective, the conventional estimation of LUC-GHG emissions induced by the provision of land for feedstock for biofuels requires the measurement of the following four main factors (Fig. 2):

(1) Effective quantity of agricultural-based biofuels supplied to which LUC-GHG emissions need to be assigned.

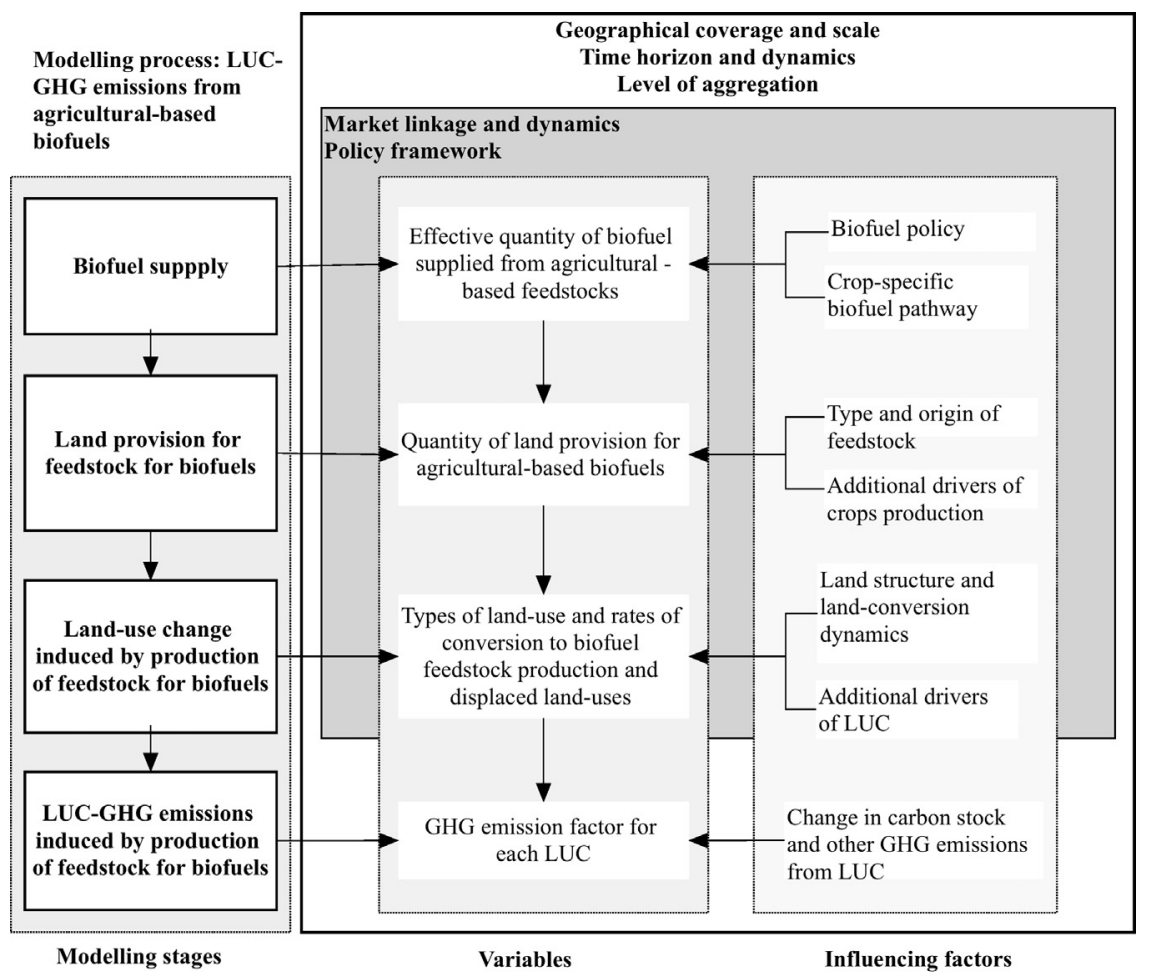

Fig. 2. Modelling process for the estimation of LUC-GHG emissions from biofuels: main variables and influencing factors. 
(2) Quantity of land provision for feedstock for agricultural-based biofuels.

(3) Types of converted land-uses and the rates of conversion into each previous land-use inducing the production of the feedstock.

(4) The GHG emission factor of each converted land-use.

Estimating LUC-GHG emissions from specific feedstocks for biofuels requires linking economic, biophysical, environmental, and social systems that evolve in space and time. Addressing this complex system leads to a variety of modelling approaches to account for the links among biofuels, LUC, and GHG emissions.

The estimation of the quantity of biofuel produced requires assessment of the specific context in which biofuels are produced. For example, agricultural-based biofuel production links agricultural products and energy markets. This interaction can generate environmental and economic impacts at the national and international levels. Accordingly, two questions were explored here: how specific biofuel pathways are represented, and how the biofuels sector is linked with other markets. A subject of further discussion is how policies are being introduced in reliance upon current models.

In this context, an analysis was performed with respect to (1) market dynamics, defined as the type of link between the biofuels sector and the domestic and international agricultural and energy markets; and (2) policy variables, defined as the policy instruments that directly or indirectly affect the supply of agricultural-based feedstock for biofuels.

Estimating the quantity of land provided for feedstock of biofuels involves accounting for other relevant factors. A large part of the impact from the production of biofuels on LUC will depend on the type and origin of the feedstock used to produce biofuels. Currently, most biofuels are produced from agricultural-based feedstocks, often cash crops that require land as the main production factor.

In the case of agricultural-based biofuels, two categories of feedstock are explored: energy crops, defined as crops cultivated directly for energy purposes; and multi-product crops, defined as crops produced for a variety of purposes (food, feed, fibre, fuel), including as feedstock for biofuel production. This review includes models that have been applied to study both types of feedstock. Energy crops may include lignocellulosic feedstock such as switchgrass, directly cultivated for processing into second-generation biofuel. Multi-product crops may include sugar cane, corn, colza, palm oil, and soybean. Most biofuel feedstocks are currently multiproduct crops that serve domestic and international feed product demands.

Apart from the demand for feedstock for biofuels, other economic and natural drivers are responsible for LUCs. Different approaches have been tried to isolate the effect of agricultural land expansion because such effects should be considered in the contexts of other relevant drivers of LUC. In this respect, previous assessments have already shown the limitation of current approaches for isolating the effects of the agricultural sector as a whole [22]. Assigning GHG emissions to biofuels requires the resolution of two fundamental problems: how to isolate the effect of crop-specific biofuels from other drivers of LUC, and how to deal with multi-product agricultural-based biofuels.

Leaving aside the problem of land allocation, other important factors are worth mentioning. In relation to land area, the supply of land for crops is affected by the possibility of using current available agricultural land and of expanding the agricultural frontier. The competition for agricultural lands is affected by the market dynamics of the agricultural sector and the policy framework regulating land management decisions. These factors in turn affect costs that influence land profitability. The provision of land for feedstock for biofuel then depends on the effect that biofuel demand has on feedstock price and how this price change translates into a change in land area.
At this point, the link between economic and location drivers needs to be addressed. Linking economic and location drivers of LUC is a major requirement for the integration of economic and spatial approaches. How will the provision of land for feedstock affect the distribution of land for other uses? If land expansion occurs, answering this question requires defining land conversion rates to the provision of land for feedstock.

The definition of the structure of the land-use system, the way to define the type of land conversion, and the rates of conversion become critical. Important questions to consider are

- Will the feedstock for biofuels expand into new land, generate changes inside current agricultural land, or induce intensification processes?

- Which types of natural and managed lands are converted?

- What are the conversion rates of land provision for feedstock for biofuels?

Concerning LUC modelling, this review then evaluates the methods for estimating LUC induced by biofuel production based on (1) land allocation and land supply structure, and (2) the links between economic and location drivers in current modelling approaches. Including GHG emissions from LUC into biofuels emission balance involves two operations: defining the use of marginal or average value for land conversions and assigning GHG emission factors to each type of converted land-use. This review explores the main approaches to dealing with LUC-GHG emissions and the available databases for defining LUC-GHG emission factors for biofuels.

The ideal modelling approach should account for LUC-GHG emissions of specific biofuel production pathways at different scales in space and time. Common issues across all stages of the estimation of LUC-GHG emissions are then further explored. These issues include: (1) geographical coverage, defined as the validity of the estimation in space; (2) time-dependence, defined as the validity of the estimation in time; and (3) level of aggregation, defined as the heterogeneity in the representation of actors and land characteristics. In this review, how these common issues are being addressed is analysed, as is how current models are being adapted, integrated, and coupled to account for different dimensions of these problems.

\subsection{Overview of modelling approaches}

Table 1 gives a general overview of selected modelling approaches considered in this paper, classified based on their purpose. Representative models of each modelling approach are indicated with their main characteristics for addressing one or several stages of modelling LUC-GHG emissions from biofuels.

Modelling each stage involves making several choices that influence the type of modelling approach applied. Fig. 3 indicates for each stage the modelling choices and the type of modelling approach used to address each influencing factor.

Computable general equilibrium (GE) models are a type of topdown economic model characterised by the integration of theory on GE with real (historical) data of a given economy in a computerbased simulation model. The theory of GE or partial equilibrium (PE) explains the relation among supply, demand, and prices through the satisfaction of a set of simultaneous equilibrium equations [25].

These two types of equilibrium models have been applied to study impacts of biofuels in LUC-GHG emissions. GE models represent the whole economy and the interactions among different sectors, and PE models provide a detailed estimate of a specific sector (or sectors) of the economy and determine hypothetical equilibrium prices for a specific market (or a limited set of markets). 
Most PE models dealing with biofuels and LUC are agricultural and energy sector models. Consistent reviews of agricultural sector models applied to the assessment of LUC induced by energy crops demand have also been performed [7,26-29].

Optimisation models are mainly applied to perform economic efficiency analyses on the impact of biofuel production [9,30-32]. They are also used to assess optimal strategies for biofuel feedstock production in terms of GHG emissions reduction [2].

Spatially explicit models focus on the spatial allocation of land resources. Concerning LUC, several authors have provided comprehensive reviews of land-use modelling approaches [33-35]. Spatially explicit models have mainly been used to account for spatial patterns in land allocation for biofuel crop production [36-39].

Biophysical models target describing ecological and environmental processes. They assess, for example, the impact of climate change on crop yields and land productivity. In the context of this review, biophysical models were applied mainly to calibrate parameters in economic models [40] or provide data on yields and land productivity $[41,42]$.

Agent-based $(A B)$ models focus on simulating individual actors' decisions. They account for local/regional actors' behaviour, preferences, and heterogeneity to simulate the emerging behaviour of the system. Parker et al. [43] and Mathews and Goldsztein [44] give extensive reviews of AB models applied to LUC modelling, but little work has been done to analyse the impact of biofuels production $[45,46]$.

System dynamics (SD) models assess the time-dependent behaviour of complex social systems, focusing on the identification of feedback structures to generate endogenous explanations of system behaviour over time. Several SD models are being used to simulate biofuel diffusion processes [47-51], the impact of biofuels production on commodity markets [52-55], LUCs [50,56-59], and GHG emissions [60-63].

Life cycle assessment (LCA) models evaluate the environmental impact of a product through the quantification of input and output flows. Although attributional LCA assesses the average environmental properties of a particular product, consequential LCA assesses the consequence of a decision [64]. GHG emission balances of biofuel pathways are treated in the literature, which addresses the main methodological challenges and how LUC can be integrated into LCA [65-68]. Larson [69], Cherubini [70], and Malça and Freire [71] provide consistent reviews of GHG emission balances of biofuels. LUC-GHG emissions from biofuel production have been addressed based on the consequential approach to estimate marginal changes in the supply of land for biofuels and their associated GHG emissions from LUC [72].

\section{Modelling biofuel supply}

\subsection{Accounting for market dynamics and interactions}

Measuring the quantity of biofuels supplied is required to assign LUC-GHG emissions to them. GE/PE, optimisation, and SD models have been used to determine land provision for biofuels based on quantity of biofuel supplied.

GE models calculate biofuel supply based on the market equilibrium assumption, i.e., when supply equals demand for each region and sector. Given an exogenous shock in feedstock demand for biofuels and all other factors being equal (ceteris paribus assumptions), prices are adjusted to clear the market. The demand level is then set to represent biofuel mandates at the national level.

SD models can extrapolate from the equilibrium and ceteris paribus assumptions because they can represent the adjustment process in time to reach equilibrium. Consequently, SD models were used to study the conditions needed to achieve the required biofuel mandate levels. In these models, the quantity of biofuel supplied depends on the effect of biofuel and accompanying policies for a given market context.

Equilibrium and optimisation can be merged when optimisation is used to maximise a welfare function, subjected to the market equilibrium assumption. REAP, LUCEA, and FASOM are optimisation models used to assess the interactions between biofuels and land provision for feedstock $[9,73,74]$. This model predefines the

Table 1

Overview of representative modelling approaches applied to the estimation of LUC-GHG emissions from biofuels production

\begin{tabular}{|c|c|c|c|}
\hline Focus on biofuels-LUC-GHG analysis & $\begin{array}{l}\text { Type of } \\
\text { modelling } \\
\text { approach }\end{array}$ & $\begin{array}{l}\text { Selected models applied to } \\
\text { biofuels-LUC-GHG analysis }\end{array}$ & Characteristics of applied models \\
\hline $\begin{array}{l}\text { Global economic impacts of biofuels } \\
\text { production } \\
\text { Estimate supply-demand-trade balance } \\
\text { Policy analysis }\end{array}$ & $\begin{array}{l}\text { General } \\
\text { equilibrium }\end{array}$ & $\begin{array}{l}\text { GTAP, MAGNET, EPPA, DART, } \\
\text { FARM }\end{array}$ & $\begin{array}{l}\text { Global, static or recursive dynamic, non-spatial, economic, focused in all } \\
\text { economic sectors, aggregated actors and regions, policy oriented }\end{array}$ \\
\hline $\begin{array}{l}\text { Global and national economic impacts of } \\
\text { biofuels production } \\
\text { Supply-demand-trade balance and policy } \\
\text { analysis for the agricultural and energy } \\
\text { sectors }\end{array}$ & $\begin{array}{l}\text { Partial } \\
\text { equilibrium }\end{array}$ & $\begin{array}{l}\text { AgLink-COSIMO, ESIM, FAPRI, } \\
\text { CAPRI, GCAM, IMPACT, PEM, } \\
\text { POLE, PRIMES }\end{array}$ & $\begin{array}{l}\text { Global or national, recursive dynamic, non-spatial, economic, sector- } \\
\text { specific focused in agriculture and energy sectors, aggregated actors and } \\
\text { regions, policy oriented }\end{array}$ \\
\hline $\begin{array}{l}\text { National economic efficiency analysis } \\
\text { Policy analysis }\end{array}$ & Optimisation & FASOM, LUCEA, P\&G, POLYSIS & $\begin{array}{l}\text { Global or national, recursive dynamic, spatial or non-spatial, linear } \\
\text { programming, focused in forestry and agricultural sectors, aggregated } \\
\text { actors and regions, policy oriented }\end{array}$ \\
\hline $\begin{array}{l}\text { Land allocation based in spatial patterns } \\
\text { Integration of biophysical variables in } \\
\text { economic models }\end{array}$ & Spatial & $\begin{array}{l}\text { CLUE, LANDShift, KLUM, GIS- } \\
\text { LTM }\end{array}$ & $\begin{array}{l}\text { Global, national and regional/local scales, static, spatial, location patterns } \\
\text { estimated by cellular automata, remote sensing or empirical-statistical } \\
\text { analysis, disaggregated actors and regions, non-policy oriented }\end{array}$ \\
\hline $\begin{array}{l}\text { Calibration of bio-physical parameters } \\
\text { Estimation of bio-physical variables in } \\
\text { economic and spatial models }\end{array}$ & Biophysical & EPIC, IMAGE & $\begin{array}{l}\text { Global, static or dynamic, spatial, focused in bio-physical and } \\
\text { environmental sectors, aggregated actors and regions, non-policy } \\
\text { oriented }\end{array}$ \\
\hline Individual heterogeneous actors decision & Agent-based & $\mathrm{C} \& S, \mathrm{~B} \& \mathrm{~S}, \mathrm{G} 4 \mathrm{M}$ & $\begin{array}{l}\text { Local/Regional, dynamic, spatial, disaggregated actors, focus on the land- } \\
\text { use system, non-policy oriented }\end{array}$ \\
\hline $\begin{array}{l}\text { Biofuels diffusion and policy analysis } \\
\text { Time delays and feedback interactions }\end{array}$ & $\begin{array}{l}\text { System } \\
\text { dynamics }\end{array}$ & $\begin{array}{l}\text { S\&G, GLUE, TIMER, BDM, BSM, } \\
\text { BioLUC }\end{array}$ & $\begin{array}{l}\text { Global, national, or regional/local, non-spatial, fully-dynamic, non-spatial, } \\
\text { focused in systemic approach, aggregated actors, policy oriented }\end{array}$ \\
\hline LUC-GHG emissions & $\begin{array}{l}\text { Life cycle } \\
\text { analysis }\end{array}$ & $\begin{array}{l}\text { Consequential LCA } \\
\text { GREET, Ecoinvent, GHGenius }\end{array}$ & $\begin{array}{l}\text { National or local, static, non-spatial, focused in feedstock specific } \\
\text { pathways, aggregated actors, policy or non-policy oriented }\end{array}$ \\
\hline
\end{tabular}


type of analysis that can be performed. Similar to equilibrium models, the main limitation of optimisation models is the assumed optimality conditions. Complex dynamic systems normally do not behave in an optimal way (e.g., supply does not equal demand). This dis-equilibrium behaviour can be addressed in dynamic models, such as SD models.

\subsection{Modelling crop-specific biofuel production pathways}

Most equilibrium and optimisation models have been used mainly to analyse climate change and agricultural policies. Consequently, significant adaptations have been required to include the biofuels sector and the link to global agriculture and energy markets.

In the case of GE models, the biofuels sector is generally modelled by linking the energy and the agricultural sectors. The Global Trade Analysis Project (GTAP) model was designed to analyse trade interaction in the global economy [25]. The GTAP-E version [75] added an explicit representation of the energy sector, improving the possibility of substitution among different sources of energy. In the Emissions Prediction and Policy Analysis (EPPA) model, biomass as fuel was introduced as a perfect substitute for fossil fuels in the refined oil sector [76]. This adaptation allowed a better representation of the link of biofuels to energy markets, an issue that was left apart to focus on the LUC-GHG discussion. The GTAP-BIO database finally includes an explicit representation of the biofuels sector [77], linking, for instance, biodiesel to the vegetable oil and fats sector. Birur et al. [78] further disaggregated the biofuels sector in the GTAP-E model. At this level of aggregation, specificities in the biofuels sector are scarcely represented, given the global scope of the assessment. Results produced from global models should be understood and analysed in the context of their global scope.

SD models better represent the specificities in biofuel production pathways. Bantz and Deaton [47], for instance, studied the evolution of the biodiesel industry in the USA, modelling the biodiesel supply chain based on four modules representing the

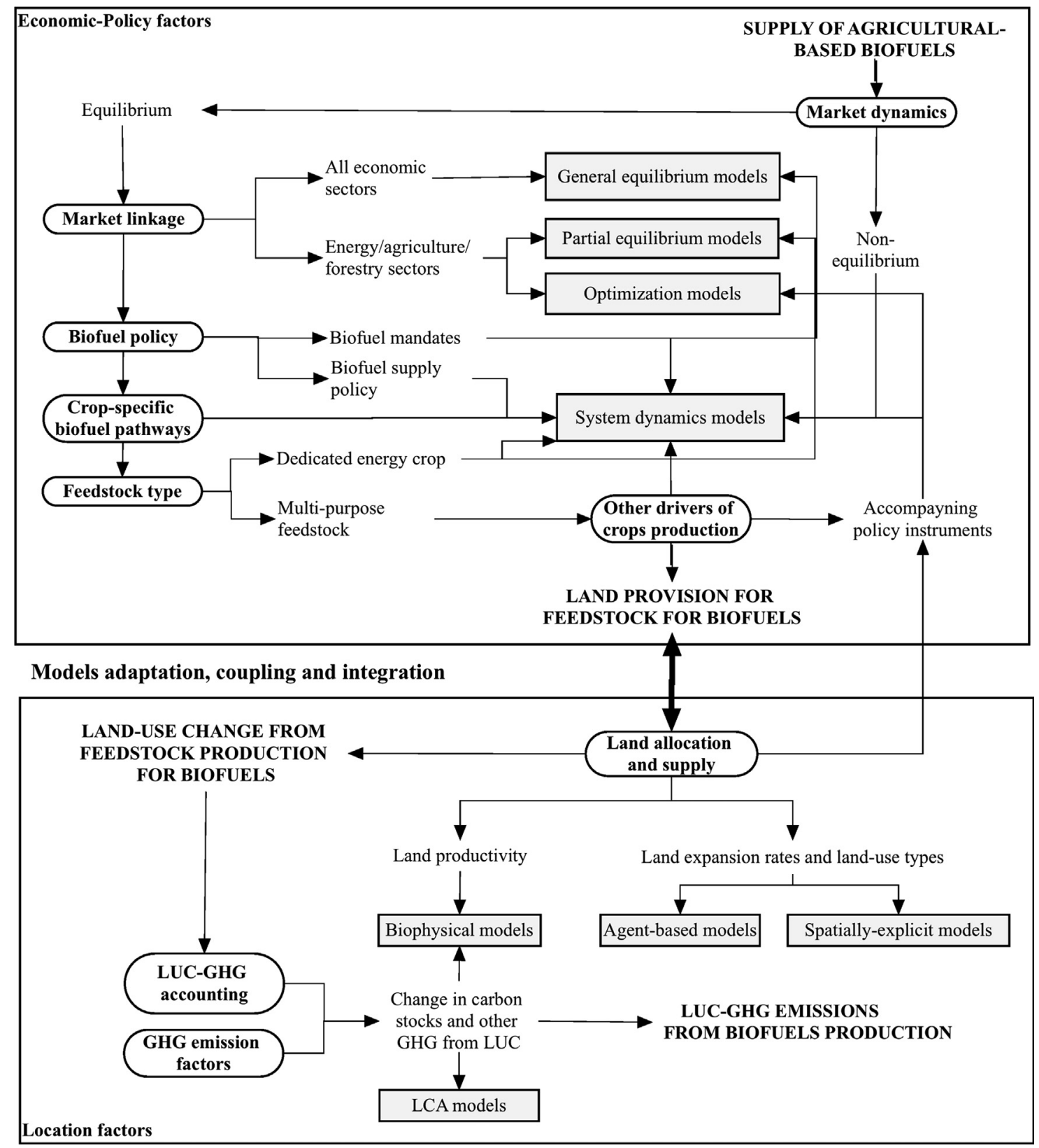

Fig. 3. Assessment of main variables and influencing factors in selected modeling approaches. 
diesel, biodiesel, glycerol, and biomass oil sectors. Their model is used to assess the effect of governmental regulations and incentives on the availability of feedstock and biodiesel/diesel and glycerol prices.

The case of multi-purpose crops used as feedstock for biofuels should be distinguished from the case of dedicated energy crops. Modelling multi-product crops involves additional complexity because additional methods must be applied to isolate the effect of biofuels and assign LUC-GHG emissions among the different drivers of the land supplied to cultivate the multi-product crop. In this case, competition arises not only at the land-use/farmer level but also at the industrial level. In the case of energy crops, there is only one economic driver of land supply for the crop. Assigning LUC-GHG emissions to biofuels is reduced to a land allocation problem between alternative uses of the agricultural land. In the case of multi-product crops, crops are already cultivated and used for other purposes.

The effect of the new demand for feedstock for biofuels should then be assessed in the context of the marginal (additional) land required to produce a certain level of biofuel. The link to agricultural markets and land-use systems then takes a more complex dimension. The estimation of the provision of land for feedstock for biofuels needs an allocation procedure to isolate the effect from other drivers of land provision. This approach should account for the diversity of crop uses and the level of pressure on land supply that each driver induces. From this perspective, the contribution of economic, social, and biophysical drivers may be understood, and criteria for allocation of emissions should be specified.

\subsection{Modelling biofuel and accompanying policies}

In equilibrium models, simulations were mainly focused on the LUC impacts of biofuel mandates, accounting primarily for the impact of USA and EU policies [10,32,79-85]. The EPPA model, for example, was used to estimate the impact of the demand for second-generation biofuels on land conversion $[76,86]$. The link to biofuel policy can be introduced as an exogenous shock in demand for biomass.

GLOBIOM is a spatial PE model of the global forest and agricultural sectors used to analyse the interaction between biofuel production and deforestation [87]. In this case, biofuel policies are indirectly accounted for by defining different scenarios of biofuel production levels by 2030 .

A key feature of biofuel policies is the combination of instruments supporting the supply and demand side of the biofuels sector. Because of the combined characteristics of biofuels as a substitute for fossil fuel and an agricultural-based product, biofuel supply is subjected to energy, environmental, land-use, and agricultural policies.

Most studies have focused on assessing the impact of biofuel mandates on global agricultural markets and particularly the impact of EU and USA mandates on global LUC. The Policy Analysis System (POLYSIS) [88], for example, was used to assess the impact of USA biofuel mandates on GHG emissions from national LUC [74]. The Modular Applied GeNeral Equilibrium Tool (MAGNET, ex LEITAP) is a modified version of GTAP model [89]. MAGNET was applied to analyse the impact of EU biofuel mandates on global LUC $[8,83,90,91]$.

The common procedure for analysing mandate impact on LUC is based on model-run comparisons between a baseline without biofuels and an alternative scenario with biofuels. The baseline projection is shocked with the required feedstock demand (or land quantity) to produce biofuel target demand given assumed technologies. A higher demand for crop-based biofuels may increase crop prices. Farmers consequently may allocate more lands to this crop to respond to the possible supply-demand imbalance, displacing other land-uses. This choice, in turn, may reduce land supply for the production of other agricultural products, increasing prices for these displaced products. Displaced production is then shifted elsewhere in response to supply and demand of goods across all markets.

The main problem with this approach is that the mandate achievement depends, among other factors, on the policy framework regulating the biofuel supply chain. Subsidies, taxes, and supply constraints, for instance, can limit the ability of biodiesel producers to supply the required biodiesel quantity to achieve mandate levels [92]. Some economic analyses have been performed to assess, for instance, the effect of tax credits in the USA [93] and the effect of the subsidies for biofuel production in selected countries of the Organisation for Economic Co-operation and Development (OECD) [94]. In equilibrium models, with the exception of biofuel mandates, little work has been done to assess how different combinations of policy instruments affect LUC induced by biofuel production.

In these cases, the effect of policy instruments is mainly tested at the national scale, as Ignaciuk et al. [95] did when assessing the impact of biomass subsidies and conventional electricity taxes using a national PE model. The model was used to determine the impact of these policies on GHG emissions, land allocation, and food and electricity prices in Poland. This type of assessment seems appropriate for linking to regional or national scale models given that more detailed data are needed to account for the specificities of the country and the national biofuel industry.

The effect of policy instruments on the biofuel supply side has been more extensively treated in SD models specifically developed for this purpose. In the context of LUC and GHG assessments, the main limitation of current SD models is, however, that their application was limited to biofuel diffusion processes. Even though they account for the effect of different policy instruments on biofuel production levels, their link to LUC and GHG emissions is hardly reflected.

Accompanying policies may significantly change biofuel production and consumption patterns, supporting or constraining the development of the biofuels industry. Some authors have explored the effect of accompanying policies, such as Johansson et al. [9], who used the LUCEA model to assess the effect of carbon taxes on land-use competition for food and bioenergy in the USA [9].

Including biofuel-accompanying policies in such models can lead to significantly different results, as may be the case, for instance, of GHG emission-saving thresholds imposed on biofuel suppliers. None of the studies reviewed account for GHG emission constraints in biofuel trade and supply.

\section{Modelling of LUC}

The possibility of expansion of feedstock for biofuels into other managed or natural land depends on the characteristics of the region where feedstock is produced. In regions where agricultural land is scarce or currently used for other purposes, the possibility of expanding agricultural land into new (natural) land is limited. Land productivity in new land in this context becomes a central issue for land conversion decisions.

Efficient cultivation methods and technological improvements can overcome lower land productivities, but at the expense of higher production costs. Regions in this condition should expect higher rates of land conversion inside the agricultural system and higher impacts on intensification processes. In the case of regions with a large availability of agricultural land, changes should be expected in the limit of the agricultural frontier, either from direct expansion of crops for biofuels or the indirect conversion of displaced agricultural 
land-uses. Expected land profits in this case should then be sufficiently higher to justify converting un-managed lands.

Three main issues were considered to be addressed when assessing LUC from biofuel production. A large part of the impact of land provision will depend on how the feedstock interacts with other land-uses. This interaction can be described based on (1) the land allocation procedure to assign productive land among competing land-uses; (2) the land supply mechanism to assess managed land expansion into unmanaged lands; and (3) the type of converted land-uses.

\subsection{Modelling land allocation}

In economic models, the traditional approach to allocating land among competing land-uses is based on the constant elasticity of transformation (CET) function [96]. Darwin et al. [97] proposed an approach relying on CET functions to represent substitution among crop sectors. Most LUC models, such as the Future Agricultural Resource Model [98] and Kleines Land-Use Model (KLUM) [99] rely on this approach.

The CET function postulates that landowners maximise total land profits by allocating their land among selected uses, subjected to the possibility of transformation among them and the availability of land. The land supply elasticity varies as a function of the CET and the relative importance of a given activity, measured as land value [81].

A characteristic of the CET function is that it allocates land based on land value; thus, it is difficult to track LUCs in physical units. This problem can be solved by assuming that 1 ha of land of one type is converted to 1 ha of another type and through conversion takes on the productivity level of the new land-use [86].

The impact of biofuel production on LUC has also been studied through SD simulation models. However, their treatment under this approach is significantly simplified. Yamamoto $[58,59,63]$ used SD to link the land-use and the energy sectors in a global scale model (called GLUE). The model evaluates the biomass resource potential for bioenergy production, including land competition among various uses of the biomass. Several SD models are being used to simulate the biofuel supply chain in the USA, including land as the main input factor in feedstock production $[51,61,100,101]$. These models' focus on the supply chain simplifies interactions with other contextual factors. In consequence, land for feedstock for biofuels is not linked to other land-uses, linking the capacity of these models to address LUC.

\subsection{Modelling land supply}

From an economic perspective, the problem with the representation of managed land supply is challenging. Because native lands are generally not under economic use, it is difficult to estimate their economic value; therefore, the estimation of land transformation based on the conventional CET function is problematic. Likely for this reason, most economic models have assumed land as a fixed input factor and allocate land only among economic uses [102]. Nevertheless, for the purpose of assessing LUC impacts of biofuel production, this approach is not sufficient because land needs to be considered as a variable to represent land expansion possibilities. To this end, some improvements have been introduced into economic models to assess the impact of the demand for agricultural commodities on the expansion of the agricultural frontier.

GTAP improved the representation of land supply by explicitly modelling land substitution between different zones within each country using data on the agro-ecological characteristics of land [103]. This adaptation allowed a more precise representation of land heterogeneity and the potential reallocation of land-uses. A specific treatment is given to land mobility across different landuses. Different models of land supply are proposed, ranging from perfectly mobile and undifferentiated to imperfectly mobile (constrained) and differentiated (nested CET function). The LINKAGE model incorporates some possible land expansions based on the variation of an aggregated land price [104].

\subsection{Defining types and rates of converted land-uses}

The third issue to be considered in representing LUCs is the definition of the type and rates of converted land-uses [22]. This feature is especially important because the share of each unmanaged land-use on agricultural land expansion largely determines the impact of biofuel production on LUC-GHG emissions [105]. The conventional approach to estimating these shares is to assume that agricultural land expansion will follow the same patterns as historical LUC trends. Particular attention must be paid to the historical influence of other drivers of LUC when using historical patterns of LUC to derive the future impact of biofuel production. Studies by Al-Riffai et al. [106] and Searchinger et al. [14] applied this approach by assuming historical shares of agricultural land expansion into native ecosystems to allocate agricultural activities displaced by feedstock production for biofuels. However, different land conversion dynamics can arise, for example, though the introduction of new policy, and scenario analysis can be used to test alternative land-conversion rates.

\subsection{Accounting for spatial patterns}

Spatial representation is a key feature in modelling LUC because of the need to address interactions between different land-uses that affect land allocation decisions. Spatial or georeferenced models typically address the spatial correlation of landuses [107]. Land allocation is mainly estimated through regression models of location variables [108,109], Markov models of transition probabilities, cellular automata [110], or neural network [111] techniques. Regression equations are mainly estimated through time series data of land-uses, obtained generally from satellite image classification or census data [34]. Transition probabilities can be estimated mainly through satellite image classification $[112,113]$ or statistical analysis [107,114]. Remote sensing can be used for the acquisition of spatial data $[115,116]$.

SD models, on the other hand, can easily integrate other noneconomic drivers of LUC, which is an advantage in modelling more complex decision processes. Thus, these models can also give a more realistic description of the patterns governing LUC from biofuel production.

\section{Modelling GHG emission from LUC}

\subsection{Marginal or average values}

The conventional approach to estimating GHG balances of biofuels has relied on the so-called attributional LCA. Under this approach, average values of inputs are used in the biofuel life cycle inventory, and average emission factors are applied in the impact assessment. Average values are typically employed at the producer level to estimate GHG emissions of specific biofuel pathways. Considerable work is being done to include land-use impacts on LCA $[117,118]$. Mean values are used to allocate GHG emissions across the total production of feedstock while marginal values serve to allocate GHG emissions across the increase in output [22].

LUCs induced by increased feedstock demand for biofuels are a typically dynamic and policy-driven process. Focusing on the policy perspectives, marginal values have been used to estimate the additional quantity of land required to produce feedstock for biofuels. Consequential LCA evaluates the changes produced in a 
system as a consequence of a decision. Thus, several authors have applied this approach to assess global - marginal - LUC induced by biofuel mandates and its effect on biofuel GHG emission balance $[14,84,119]$.

\subsection{Selecting emission factors for LUC}

Emission factors need to be estimated to calculate GHG emissions from LUC. LCI databases provide emission factors for the processes and inputs included in biofuel LCI. Some commonly used LCI databases include GREET, Ecoinvent ${ }^{\mathbb{R}}$, and GHGenius.

The GREET model comprises an extensive database of USA transportation options, including different fuel and vehicle types. It has been mainly used to perform LCA of biofuel pathways that are considered in USA biofuel regulation. Ecoinvent is mainly a database of European LCI data [120] and has been widely applied to perform LCA of biofuel pathways [121]. GHGenius is a LCA model for the transportation sector, maintained by Natural Resources Canada.

Currently, none of these databases explicitly incorporates emission factors for LUC. Because the estimation of LUC emission factors is more uncertain and variable than others, modellers are finding ways to integrate these emission factors into policyoriented models. In the meantime, some LCA models have linked LUC-GHG emission factors from other sources.

The estimation of LUC-GHG emission factors, however, is still controversial. LUC-GHG emission factors are derived from the change in carbon stocks in land, below and aboveground biomass, and additional processes capturing or emitting GHG. Different GHG and LUC processes can then be included in the estimation.

Emission factors are also highly dependent on the type of land cover and activity of each previous and current land-use. Different types of land-uses are then associated with different GHG emission factors. There is still no consensus about which type of landuses should be included or how land should be classified. The classification of land-uses should be in line with the possibility of estimating emission factors for each specific LUC.

\section{Adaptation, coupling, and integration of models}

LCA models include LUC-GHG emissions induced by biofuel production but require coupling with other modelling approaches, development of more simple but integrated models, or the expansion of existing models.

\subsection{Coupled models}

Coupled models are more complex than integrated ones. Because outputs remain independent from each of the models that have been coupled, the models can be adapted to address problems at different scales. Moreover, complex descriptions of the economic and biophysical drivers of biofuel production and their impact on LUC-GHG emissions can be created by linking models that treat each specific issue.

Here, model coupling used in different approaches is reported to show the types of models and logical sequence to link independent models that allow estimation of LUC-GHG emissions induced by biofuel mandates. Searchinger et al. [14] coupled the FAPRI global PE model [122] with the GREET LCA model to estimate dLUC and iLUC GHG emissions induced by corn-based ethanol production required to achieve the USA ethanol mandate. The FAPRI economic model estimates two types of iLUC: the quantity of land required to relocate displaced corn production for other purposes and soybean displaced from rotation in the same land. Shares of converted land types are assigned based on the proportion of lands that has been transformed into cropland in the past. These data are used as input for GREET to calculate the GHG emission reduction potential of USA corn-based ethanol.

The USA EPA implemented a more sophisticated modelling framework, coupling PE and GE models, optimisation, and LCA models [84]. The impact of USA biofuel mandates on global and national LUC is estimated by linking GTAP with FAPRI, a GE and PE model, respectively. LUCs at the country level are estimated through the FASOM spatial explicit optimisation model of the USA agricultural sector. LUC-GHG emissions from biofuel production are estimated based on the historical share of converted landuses and emissions factors estimated by Winrock [123] based on carbon stock changes between land-use types. Similarly, these data are used as input into the GREET model to estimate biofuel GHG emission balance.

In the case of the EU, the spatial patterns of biofuel crop distribution were studied linking economic, biophysical, and spatially explicit models. The coupled model links MAGNET, the IMPAGE, and the Dyna-CLUE models [36,85], respectively. The dynamic version of the CLUE model is a spatially explicit model for the analysis of spatial patterns of LUC [124,125]. CLUE mainly uses regression analysis to estimate land-use transitions based on a set of location variables that are assumed to guide landmanagement decisions on land allocation.

The coupled MAGNET-IMAGE-CLUE model constructs a spatially explicit, multi-scale, quantitative description of LUCs through the determination and quantification of location factors of land-uses based on the actual land-use structure. The approach determines the location of crop expansion and consequently the direct LUC induced by biofuel feedstock production.

A coupled approach has also been proposed by Popp et al. [126] to address biofuel and LUC interactions, linking a global vegetation and hydrology model (LPJmL), a global land-use optimisation model (MAgPIE), and the global energy-economy-climate model (ReMIND). LPJmL is a spatially explicit model that simulates biophysical, biogeochemical, and hydrological processes in the global land surface. MAgPIE is a mathematical programming model covering the most important agricultural crop and livestock production types in 10 economic regions worldwide. The nonlinear objective function minimises the total cost of production for a given amount of regional food and bioenergy demand. Finally, ReMIND is an integrated modelling framework that links an energy system model with a macro-economic inter-temporal growth model and a climate change model that simulated the effect of GHG emissions on global mean temperature.

Modellers have made great improvements in model coupling. It is also true, however, that more detailed analysis is required. Golub et al. [127], for example, introduced the possibility of conversion of unmanaged forest land to land under economic use by coupling GTAP with an inter-temporal forestry model for better representation of the forestry sector. In each region, the supply of new land depends on the net present value of land returns, i.e., benefits are high enough to cover the costs of accessing new land. Thus, model coupling allows treating in more detail complex issues that can then be linked to a bigger model. Couple models dealing with biofuels and LUC need to be extended to cover other dimensions that are still roughly represented. The case of forest dynamics is one example.

\subsection{Integrated models}

Endogenous estimation of LUC-GHG emissions has also been improved in economic models [128]. Ahammad and Mi [129] extended the GTEM model to allow modelling LUC and associated GHG emissions. However, although integrated models can be useful for a cohesive and holistic representation of the system, 
coupled models tend to give a more detailed representation of the interactions governing the system.

The main advantage of integrated models is that because the model is developed in the same modelling environment, consistency is increased and adapting and transforming outputs beyond the original intent of the model is avoided. Integrated models are more robust in terms of linking different independent modules, but this consistency is gained at the expense of simpler representations of the system components.

Most integrated approaches were implemented in SD models. Although it is true that simple models cannot account for the complexity of the system being analysed, it is also true that very complex models are also difficult to understand, construct, and use. Thus, some simplifications are appropriate in the quest to understand complex systems.

The reviewed SD models, however, rely on simple structures that mimic the overall behaviour of the system. Although this reliance can be an advantage to avoid model coupling, when data are limited or when exploratory assessments are performed, it can be a simplistic approach for quantitatively analysing complex interactions. To this end, SD models can be used as exploratory tools to further perform more detailed assessments.

On the other hand, integrated models that link different modelling approaches can elucidate the complex dimension of time and space dynamics. Scheffran and Ben Dor [39], for instance, focused on integrating $\mathrm{SD}$ and $\mathrm{AB}$ modelling in a spatially explicit model to account for the space-time dependency of LUC in biofuel production. They assessed land competition for bioenergy crops in Illinois, including corn, soybean, miscanthus, and switch-grass biofuel feedstock. The integrated model maximises the profit of individual farmers based on crop selection and cost minimisation. Thus, an additional effort needs to be directed to develop integrated approaches that are capable of addressing time-space interactions.

\subsection{Linking economic variables with location factors}

Modelling approaches have applied two strategies to account for economic-spatial interactions, namely inclusion of economic features in spatially explicit models and inclusion of spatial features in economic models. The main limitation of spatially explicit models is that because they focus on location patterns, their representation of economic drivers of LUC is limited. This limitation motivated the link of spatially explicit models with economic approaches. The KLUM was linked to a modified version of the GTAP model to account for macro-economic variables driving land allocation decisions [37]. Replacing the land allocation mechanism of GTAP with KLUM links the models. In the coupled model, land allocation in KLUM depends on the profit maximisation decision of the landowner in response to GTAP equilibrium prices. The biophysical characteristics of land that define crop yield are exogenously introduced by linking KLUM to the Lund-Potsdam-Jena dynamic global vegetation model. Although no application to biofuel LUC-GHG emissions has been performed with this coupled model, it is clear that the need to link economic and location variables is not specific to the biofuel context but is an issue that needs to be addressed in any LUC model. In this respect, addressing biofuel impact has helped with exploration of the challenging issues of LUC modelling.

Biophysical data can be used to calibrate land supply functions based on marginal productivity information [40]. The advantage of this approach is that asymptotic limits to land expansion and decreasing returns to scale can be modelled explicitly [82]. The transformation elasticity can be estimated, for instance, using land-use transition probabilities [130]. A conventional approach for this estimation is to use time series data or satellite images
$[131,132]$. Thus, there are good perspectives on the linkage of economic and location factors; however, using transition probabilities would require detailed geo-referenced data and additional computational efforts.

\section{Definition of aggregation issues}

\subsection{Selecting the level of aggregation}

The level of aggregation of region and sectors is linked to the model scale. Most economic models aggregate regions and sectors. In the case of GE models, because they focus on the whole economy, their representation of sectors and regions is highly aggregated. The GTAP model, for instance, is a multi-regional model of 16 regions and 21 sectors. This GTAP 6 database accounts for 87 countries/regions and 57 products/sectors. The level of sector aggregation does not allow modelling decisions on biofuel feedstock type, especially for the case of biodiesel where oilseeds and oleaginous fruits are treated as a single aggregate. Furthermore, the type of region aggregation makes some models less suitable for assessing effects in specific countries. In the EPPA model, for example, because of its focus on climate change policies, regions were aggregated into Annex B and Non-Annex B countries of the Kyoto Protocol. This approach may bias the assessment of LUC impacts of biofuels because large players on the biofuels and agricultural market are also aggregated. Consequently, detailed information of the national biofuel and agricultural sectors may be missing in models where the type of country/ region aggregation responds to other criteria.

Current GE models account only for a few biofuel production pathways, namely sugar cane, sugar beet, and coarse-grain ethanol (GTAP, MAGNET), wheat ethanol (MAGNET), and average lingocellulosic ethanol (EPPA). This type of aggregation can be suitable for assessing global impacts of biofuel production but is less suitable for specific biofuel production pathways. This reduced suitability exists because it is impossible to track a specific biofuel supply chain. Feedstock selection by a biofuel producer within the country is not possible, and regional specificities are not accounted for, constraining the ability of global models to assess specific biofuel supply chains. Therefore, complementary models are needed that focus on specific biofuel production pathways.

\subsection{Accounting for the heterogeneity of actors}

Most models have an aggregated representation of actors independently of the model scale, which may occur because large-scale models required large sets of global data, data are missing, or the scope of the assessment does not require the disaggregation of actors. Equilibrium models are typically aggregated models. GE models represent the whole economy through aggregated economic actors at the national level. The GTAP model, for example, represents the global economy as a multi-region economy. Each regional economy is modelled by a representative household, which maximises utility, and a set of producers of specific goods and services, which maximise profit. In each region, the model assumes a single representative producer of each good. Although this aggregation level is necessary to handle global models, actor homogeneity makes the model less suitable for assessing actor-oriented biofuel policies.

The Brazilian Biodiesel Program, for instance, explicitly supports small agricultural producers [133], and the Argentinean biodiesel policy [134] explicitly supports small and medium biodiesel producers. Accounting for these national policies may require disaggregation of actors at least at the country level. Moreover, beyond the national biofuel policy, several regions have 
implemented additional policies to support their local biofuel industry. At this stage, if the model aims to assess the effect of local biofuel policies, further disaggregation of actors is required. Accounting for these policies may significantly influence the location patterns of feedstock production.

Actor heterogeneity is better represented in AB models. Parker et al. [72] provide several examples of multi-agent LUC models that focus on individual heterogeneous agents. Because AB models focus on simulating actor decisions, they overcome some limitations of equilibrium and SD models mainly by including different actor types and individual decision-making processes.

For instance, Rossetti et al. [135] assessed the market diffusion of second-generation biofuels in Austria. Products are differentiated based on multiple attributes such as price, quality, or environmental performance. The level of detail required to account for actor heterogeneity, however, makes these models most suitable for regional or local applications.

Another example is offered by the Stanford-Carnegie Biofuels Project. The Stanford-Carnegie Project uses AB modelling to assess the effects of sugar cane-based ethanol production on land-use distribution in northern Brazil. The model simulates farmer response to increased demand for sugar cane and the displacement effects on competing land-cover classes [136]. Unfortunately this type of model is not commonly found in the biofuels-LUCGHG literature. Most modelling approaches focused on assessing global impact of biofuels production on LUC.

SD approaches, on the other hand, have relied on relatively simple models with an aggregated representation of actors. In Stamboulis and Papachristos [51], for instance, the simple SD diffusion model is divided in three sectors: feedstock production, biofuel production, and biofuel use. Feedstock production is centred on the provision of land. Biofuels production is represented by the investment in production capacity, and biofuels use is based on the availability of retailing sites and consumer demand. Each process is represented by an aggregated actor (i.e., farmer, biofuel producer, consumer), which determines the dynamics of the transition to biofuels.

Then, with the exception of $\mathrm{AB}$ models, the level of aggregation of actors in existing models needs to be refined to account for the effect that different types of actors have on biofuel supply. Accordingly, if there are different types of producers, modellers need to define the level of disaggregation. This disaggregation level should be in line with the type of policies and market structure affecting the biofuel supply chain.

\subsection{Land heterogeneity and aggregation}

LUC modelling requires accounting for land heterogeneity. Disaggregation is then required to account for different types of land, mainly in terms of productivity, carbon stocks to assess LUC, and related GHG emissions from biofuel production. Moreover, the use of certain types of land for biofuel production has been regulated in biofuel policies. Consequently, disaggregation is also required to assess the eligibility of biofuel production locations.

Considerable work has been done to account for different land productivity levels. In the reviewed economic models, land is mainly disaggregated based on geo-referenced classification of agricultural and forest land-use data. For instance, Monfreda et al. [137] provided geo-referenced average harvested area and yield values for 175 individual crops at the global scale. Lee et al. [138] disaggregated land-use by AEZ based on global land-cover databases. Each AEZ defines a parcel of land with similar agroecological characteristics, such as precipitation, temperature, soil type, and terrain conditions, and with a similar combination of constraints and potential for land use. This extension of the standard GTAP database allows a more refined description of feedstock location patterns and a better modelling of LUC impacts of biofuel production.

Much effort has been also made to improve the disaggregation of national land-use data in global models. In the FAPRI model, for example, land heterogeneity is specifically detailed for the USA and Brazil [139]. Nonetheless, the representation of land heterogeneity at the national and global scales is still rough. Most developments at the national level rely on global land-use databases. Because their resolution is rough, classification of land-uses sometimes does not match the real landscape, which is a problem for estimating the impact of biofuel policies on LUC because of biased induced by the misclassification of land-use data [140].

Disaggregation of carbon stocks in land is necessary for the estimation of LUC-GHG emissions. Consistent work has been put into representing carbon stock heterogeneity in land and the estimation of carbon stock changes. For example, Houghton and Hackler [141] provided annual estimates of the net change in carbon from deliberate changes in land-cover and land-use. Emission factors are especially estimated for forest clearing for agriculture and the harvest of wood for wood products or energy.

In the context of the assessment of biofuel LUC-GHG emissions, Winrock International [123] estimated the extent of recent landcover change at national and sub-national scales for all countries using data derived from satellite imagery. GHG emission factors for various land-cover conversions are estimated using guidelines of the Intergovernmental Panel on Climate Change (IPCC) [142]. Results from Winrock's analysis were incorporated into the EPA's RFS program [84]. Specific land-use classes important for LUCGHG emissions, such as wetlands, have been defined. However, in terms of disaggregation, more efforts are required in, for example, the disaggregation of carbon stocks by crop types.

Land disaggregation is also required to study the eligibility of regions as feedstock production areas. In the EU-RED [5], for example, command and control instruments are used to regulate feedstock location. This criterion implies that feedstock cannot be cultivated in forestland with more than 30\% canopy cover Accounting for this criterion will imply disaggregating forestland in different types.

Some work is being done to overcome this limitation by adapting existing land-use databases $[143,144]$. However, this adaption and integration into models and policy analysis is still under development.

Finally, in some cases, biofuel policy aims to promote cultivation in certain land-use types. In the EU-RED, a credit is given for energy crop cultivation in set-aside land. In that case, further disaggregation of land-use types is required. These constraints and incentives for selected land-uses can significantly change land-use allocation patterns. Then, modelling approaches need further development for the integration of specific land-uses critical in the assessment of LUC-GHG emissions.

\section{Geographical coverage and scale issues}

\subsection{Definition of geographical coverage}

Scale choices are sometimes limited by the underlying structure of models. Geographical coverage has been addressed in two ways: the model scale defines the type of assessment, or the type of assessment defines the model scale.

In the first case, GE models have been mainly applied to assess the worldwide implications of biofuel production. In the context of this assessment, the typical scale of these models is the whole world.

The AGLINK-COSIMO model, for example, is a dynamic multiregion model of the world agricultural sector. The model is used to estimate the impact of biofuel production on land requirements to 
cover biofuel demand $[145,146]$. Global equilibrium models represent the whole world and then focus on assessing international iLUC [17]. Although it is pertinent to use a worldwide scale model for this purpose, national specificities are very simplified. Thus, this type of model should be chosen to assess global integrations, but it should be kept in mind that important simplifications are being made inside these global models.

The use of equilibrium models at the national scale to assess bioenergy impacts on LUC is less common, however. Ignaciuk and Dellink [147], for instance, proposed a national equilibrium model to estimate the role of multi-product crops for bioelectricity generation in Poland. They focus on the competition between agriculture and bioenergy for limited land resources and changes in land allocation. The main advantage of their application is the acquisition of a detailed description of the sector under study and its implications for the national economy. On the other hand, in national scale models, several simplifications, such as the link to global markets, need to be made because physical system boundaries are fixed at the nation's border. Thus, there is room for improvement in the linkage of global and national economic models.

With respect to scale and geographical coverage, therefore, two main issues need to be solved in economic models: the representation of market forces at different scales and the linkage of these forces between scales and with other modelling approaches.

Spatially explicit models provide the flexibility to assess the impacts of biofuel production on LUC at different space scales. Although scale choice is critical, the literature provides examples of global, national, and regional scales in spatially explicit models. Multi-scale analysis of land-use driving factors and their application in spatially explicit modelling are crucial in assessing local and global impacts of biofuel production on LUC [148].

Li et al. [149] proposed a spatial modelling framework to simulate long-term, regional changes in croplands and short-term, local fluctuations (such as rotations). The approach integrates a spatially explicit model and a land transformation model. A shortterm non-consecutive layer of past land-cover data is used to calibrate the neural network of the land transformation model and produce a forecast for 2020 of biofuel cropland spatial distribution in North Dakota.

$\mathrm{Wu}$ et al. [42], on the other hand, proposed an integrated modelling framework to simulate individual agricultural producer decisions on sown areas of major crops in a global scale. The integrated modelling framework focused on inter-cropland LUC links a crop yield model (Geographic Information Systems-based Environmental Policy Integrated Climate, or EPIC), used to estimate yields of different crop types under a given biophysical and management environment; a crop price model (International Food Policy and Agricultural Simulation, or IFPSIM), employed to assess the price of crops on the international market; and a crop decision model to assess crop allocation by individual farmers. This attempt is the first to account for local drivers in global models.

Provided that $A B$ models focus on individual decision-making processes, aggregations may not be desired. Detailed data are required to develop models of heterogeneous actor behaviour, and scale in $A B$ models is generally limited to local/regional applications. For instance, an integrated SD-AB model was used at the county level to assess land-use competition for bioenergy crops in Illinois [39]. Data requirements may reduce AB model applicability for estimating the impact of national biofuel policies and their impact on global markets.

SD models have been applied mainly at the national scale to assess the evolution of the biofuel industry. Several SD models are being used to simulate the biofuel supply chain in the USA $[47,48,100,101]$. Alternatively, studies by Sheehan $[60,150]$ addressed the global LUC induced by cellulosic bioethanol production in the USA. The model does not, however, account for economics and focuses mainly on estimating the GHG emission balance of USA ethanol.

Models at the regional scale have been developed in SD. Szarka et al. [62] proposed a model to assess the impact of bioenergy production on GHG emissions at the Austrian-Hungarian crossborder area. An advantage of SD models is that implementation of scale issues is more flexible and scale can be set to fit the research purposes. This adjustment is possible because data requirements are less strictly needed, as the modelling technique focuses on describing the time behavioural patterns of the system.

\subsection{Relation of model scale to system boundaries}

The choice of scale is associated with the selection of the system boundaries. The system boundaries are fixed based on the processes included in the estimation of biofuel GES. In the case of LUCs, these processes may include direct LUC from the supply of land for the feedstock production, indirect LUC from the displacement of other land-uses or uses of the biomass, and the "credit" for co-products supply. The system boundary of the model can derive from biofuels policy. In the EU-RED, for example, only GHG emissions from direct LUC are included. On the other hand, in the USA EPA-RFS, both direct and indirect LUCs are included.

Concerning biofuel impact on LUC, several GE models have been used to assess global iLUC [17]. They account for land-use displacements in other countries resulting from increased demand for biofuel feedstock in countries/regions with a biofuel mandate. Global agricultural commodity markets make it possible for iLUC to occur in other countries, which justifies the choice of a global model. On the other hand, if only dLUC GHG emissions are included (as in the EURED case), a more detailed national scale model may be preferable. Indeed, in the EPA approach, a global GE model is linked to a national PE model of the USA agricultural sector. Model linkage is helpful in expanding system boundaries while preserving the level of detail required to asses LUC impacts at different scales. National scale models can be adapted to deal with biofuel policies that focus on a particular biofuel pathway. Thus, the challenge is how to couple models at different space scales.

Accounting for the impact of co-product production also requires a global approach. Co-products from biofuel production, such as meals and dried distilled grains with solubles, can be used in the animal feed industry as substitutes for grains. Global GE models can be used to estimate the international consequences of increased co-product availability, as Taheripour et al. [77] did in using the GTAP model to analyse the impact of co-products from biofuel production on LUC at the global level.

In SD models, on the other hand, the linkage to international markets has been treated in a simplified way, mainly focused on selected biofuel supply chains at the country level. Indeed, the expansion of the model boundaries to account for global issues in SD models led to a simplified representation of the national biofuel industry.

Three approaches were considered to account for global economic markets in SD models, namely exogenous introduction of reference price scenarios, endogenous simulation of price, and price linkage to global economic variables. Exogenous prices can be modelled based on different scenarios for biofuel feedstock and fuel prices [47-49]. On the other hand, several recent studies applied Sterman's generic commodity market model [151] to give an endogenous explanation for changes in prices at the country level, as when Jahara et al. and Shri Dewi et al. [52,55] studied the impact of biofuel demand on the Malaysian palm oil industry. Endogenous simulations are useful for understanding business cycle dynamics, but in these applications, they disregard other exogenous variables affecting price. 


\section{Accounting for time-dependence}

\subsection{Modelling time dynamics}

A distinction should be made regarding the short- and longterm effects of biofuel production. The approach to accounting for time in models influences its prediction capacity and its adequacy for evaluating different effects in time. Although some models are more suited for assessing long-term impacts, others may be preferable for short- to medium-term analyses. Actors may produce a short-term effect that generates conjectural market changes that then disappear. Structural changes, on the contrary, are typically observed in the medium or long term. For instance, biofuel production may significantly increase commodity prices in the short run that may be also associated with stock availability and the influence of meteorological conditions.

In the long term, high commodity prices may encourage new producers to come into business, increasing supply and reducing prices. Although producers need time to adapt their market expectations and take production actions, policies also need time to be designed and implemented. Land conversions between managed lands, for instance, are typically short- to mediumterm conversions because it is relatively easy to convert land among economic land-uses. Expansion into natural land requires a longer period because conversion costs are higher and legislation sometimes constrains expansion possibilities.

Three approaches were applied to account for time dynamics: comparative-static, recursive-dynamic, and fully inter-temporal.

Static models assess the reaction of the economy at a given time independent of the reaction at any other time but the reference year. For instance, the GTAP model version used to address the impact of biofuel policies on LUC is a comparative-static model that solves equations for the year 2020, with a base year in the 2007 economy.

Recursive-dynamic models solve for two successive years, taking as reference the previous period. For instance, the EPPA model solves in a recursive 5-year interval, modelling the 1997 world economy from 2000 to 2100, and is more suited for long-term analyses. FAPRI is a recursive-dynamic model that solves simultaneous equations each year, more suitable for short- to medium-term analysis.

The FASOM model has been extended to include simulation of GHG emissions from LUC [152]. FASOM-GHG yields a recursivedynamic simulation of prices, production, and consumption and GHG emissions under the chosen policy scenario. It is a recursivedynamic, multi-period, inter-temporal, price-endogenous, mathematical programming model depicting land transfers between and within the agricultural and forest sectors in the USA. The model is medium- to long-term oriented with simulations typically extending from 40 to 100 years on a 5-year time-step basis.

The POLYSYS [88] modelling framework is a set of coupled modules that form a modified type of Equilibrium Displacement Model of the USA agricultural sector. Endogenous variables are measured as proportionate change, responding to exogenous changes. The advantage of POLYSIS is that it can be calibrated to any exogenous database. Crop demand and prices are estimated through the simultaneous solution of a set of equations using an iterative optimisation algorithm. The model forecasts prices, demand, and production recursively for the next year, based on average values of the previous 2 years of data.

Wong and Alavalapati [153] proposed the Global Change Assessment Model, a global, recursive-dynamic, economic PE model that solves in 5-year time steps to the year 2095. The model was applied to assess the expected reduction in the carbon intensity of the upstream stages of advanced biofuel production due to shifting global agricultural productivities and land-use patterns [154].
Inter-temporal or fully dynamic models solve for two successive periods, but the time step can be set significantly small to capture the dynamics of the change. Inter-temporal models can provide insights on both the short- and long-term effects of biofuel production. Based on the FASOM-GHG model, Latta et al. [155] developed an inter-temporal PE model of the forest and agricultural sectors to assess the effect of biomass electricity expansion on LUC and GHG emissions in the USA. At different points in time, inter-temporal optimisation procedures yielded different biomass feedstock portfolios and GHG performances. They analysed the implications of restricting feedstock eligibility, LUC, and commodity substitution, highlighting the importance of dynamic considerations.

GE models used to assess biofuel impact on LUC are static or recursive-dynamic models. Static and recursive-dynamic models share in common the use of a baseline year to which outputs are referred. However, in the static model, we have only two points in time (the initial and final year) while recursive-dynamic models divide this time period into finite intervals (e.g., 5 years), providing a clearer representation of the evolution of the system over time. These models have proved useful for assessing structural changes in the medium to long term. The MAGNET model, for example, focused on the analysis of long-term land-use dynamics due to biofuel introduction [156,157].

On the other hand, the static approach implies some limitations in representing time-dependent processes. For instance, the study of transitional economies and the fast-growing biofuel industry requires a dynamic systems approach. In these cases, the static assumption for the representative economy may bias the simulation and forecasting accuracy of the model. Transitional economies, such as Brazil, Argentina, and Malaysia, are expected to play a significant role in biofuel production because of the availability of feedstock. In contrast, developed countries are investing in biofuels research, leading to the emergence of new biofuel technologies that, for instance, can reduce competition for land. These aspects are essentially treated in fully dynamic or intertemporal models.

Although economic and optimisation models can be dynamic, time dynamics are mainly addressed in SD models [54,60,61,100,101]. SD applies an integration (and differentiation) approach to capture the rate of change of time-dependent variables. The time-step of the simulation can be set quite small to simulate near-continuous time behaviour. Because time is considered a variable, the approach allows exploring short- and long-term effects of biofuel production over any projected period.

The BioLUC model $[23,158]$ is a SD simulation model for global LUC that focuses on the evolution of LUC based on the change and interaction over time of crucial socio-economic factors. The model was used to explore different scenarios of biofuel demand and their implications for LUC. Simulations allow assessing the sustainability of biofuel production in the context of other relevant factors, including population growth, crop agricultural yields, and supply and demand of land-based agricultural products [23].

\subsection{Discounting GHG emissions}

GHG emissions from LUC differ not only in amount but also in their discharge patterns over time, which implies discounting emissions to make policy decisions about the impact of biofuel production [159]. The conventional method to account for time in the assessment of LUC-GHG emissions is based on a "straightline amortisation" approach. GHG emissions from carbon stock changes in land due to feedstock expansion are equally divided over time, assuming a fixed period during which the feedstock is assumed to be cultivated in a certain type of land. In the EU-RED, for instance, this time period is set at 20 years. 
De Gorter and Tsur [160] supported this view by proposing a GHG reduction standard that accounts for a range of discount rates and an upper bound on the GHG payback period. In the EU-RFS, GHG emissions from LUC are discounted to account for the present consequences on LUC of biofuel production. Moreover, the time dependency of GHG emissions from biomass production was also addressed in work by Szarka et al. [62]. Their model simulated the change in $\mathrm{CO}_{2}$ emissions from regional biomass alternatives for energetic purposes, which allowed for a good representation of the evolution of GHG emissions over time. However, although several approaches are available to discount LUC GHG emissions, there seems to be no consensus on the approach or approaches that should be included in policy.

\section{Concluding remarks}

The assessment of the impact of biofuel production (and policy) on LUC and its effect on GHG emissions involves understanding the complex and multiple interactions that need to be considered at different time and space scales. Model integration and coupling seems to be the way to address this complex system. It is concluded that coupled models are more suitable for addressing global LUC-GHG emissions while integrated models should be reserved for evaluating effects at national/regional scales. The estimation of LUC-GHG emissions from biofuel production needs both complementary approaches. However, a problem still persists regarding linking approaches between models that focus on different aspects of the LUC-GHG issues, as well as addressing different time and space scales. Although this review focused on the modelling aspects, these issues remain quite important for future analysis in the case of data generation and the development of consistent databases.

Considerable progress has been made in coupling economic, biophysical, LCA, and spatial models, but several areas have been identified for improvement, including the representation of specific biofuel production pathways; the inclusion of more complete policy frameworks; the accounting for forest dynamics and local drivers of LUC; the modelling of spatial heterogeneity of LUC patterns and associated GHG emissions; and the time-dependency of effects. Examples of these applications exist, but they have yet to be linked to the assessment of LUC-GHG emissions induced by the provision of land for feedstock production for biofuels. Modellers need to take advantage of the available examples and the capabilities of computer-based simulation and more advanced modelling techniques.

On the other hand, integrated models provide a more consistent representation of the interactions among biofuels, LUC, and GHG emissions, avoiding problems of different time and space scaling. Indeed, the reviewed models have a unique time horizon and modelling approach for time and a unique spatial coverage and land disaggregation approach. A compromise then needs to be found between consistency and complexity that captures simultaneously the holistic and complex dependence of LUC-GHG emissions from agricultural-based biofuels on global market forces and the specificities of local conditions.

How to isolate the effect of biofuels remains a subject of discussion. Independently of the case of biofuels, the isolation of LUC from the agricultural sector and the assessment of crop-specific biofuel pathways have already been reported as an unsolved problem. Thus, more robust estimates cannot be expected in the case of biofuels, where additional complexity is involved. The marginal approach to iLUC is considered valid for the case of dedicated energy crops. Regarding multi-purpose feedstocks, additional steps are required to isolate the effect of biofuels. LUC from multi-purpose feedstocks needs to be assigned among the different uses of the feedstock that respond to market-driven forces. At least in the case of economicbased approaches, it is proposed that this allocation be made using the market value of products. In the case of other non-market LUC drivers, allocation procedures still need to be developed to isolate the effect of biofuels on LUC.

Inclusion of LUC-GHG emissions from biofuels in policy then needs to account for the current state of the art in the estimation. Although it is true that high uncertainty is linked to the estimation of LUC-GHG emissions from biofuels and that part of this uncertainty comes from the limitations of current methodologies, models have also been largely improved and linked to account for local and global drivers and capture the specificities of biofuel production, LUC, and GHG emissions.

There is also room for further developing current approaches with more consistent data and methodologies. The inclusion of iLUC into regulation or the monitoring of its effects remains an issue to be solved. Governments have adopted different approaches that also influence the type of models being used to address LUC-GHG emissions from biofuels.

Clear procedures and common guidelines, however, are required to harmonise reporting. In this paper, key modelling issues that influence the estimation of LUC-GHG emissions from biofuels are identified and discussed. Consideration of these aspects can help in the development of guidelines for reporting LUC-GHG emissions from biofuels. Using this guideline can help modellers to define the most suitable modelling approaches and policy makers to understand the underlying assumptions of the estimation of LUC-GHG emissions from biofuels and the implications for inclusion of LUC-GHG emissions in policy.

\section{Acknowledgements}

This research was performed in the framework of the Ph.D. work of Dr. Luis Panichelli, under the supervision of Prof. Edgard Gnansounou. We thank all of those who collaborated in the research as well as the jury members of the Ph.D. dissertation committee. The electronic version of the Ph.D. thesis is available at http://infoscience.epfl.ch/record/174796/files/EPFL_TH4974.pdf. We acknowledge anonymous reviewers for their contribution in improving this manuscript.

\section{Appendix A. Supporting information}

Supplementary data associated with this article can be found in the online version at http://dx.doi.org/10.1016/j.rser.2014.10.026.

\section{References}

[1] van Dam J, Junginger M, Faaij APC. From the global efforts on certification of bioenergy towards an integrated approach based on sustainable land use planning. Renewable Sustainable Energy Rev 2010;14:2445-72.

[2] Panichelli L, Gnansounou E. Estimating greenhouse gas emissions from indirect land-use change in biofuels production: concepts and exploratory analysis for soybean-based biodiesel production. I Sci Ind Res 2008:1017-30.

[3] CARB. Low carbon fuel standard (LCFS). California: Air Resource Board, California Envrionmental Protection Agency; 2009; 63.

[4] EPA. Regulation of fuels and fuel additives: changes to renewable fuel standard program: final rule. Renewable fuel standard program (RFS2). Washington, DC: Federal Register; 2010; 14669-5320.

[5] EC. Directive 2009/28/EC of the European Parliament and of the Council of 23 April on the promotion of the use of energy from renewable sources and amending and subsequently repealing Directives 2001/77/EC and 2003/30/ EC. In: European Commision, editor. Bussels: Official Journal of the European Union; 2009. p. 16-62.

[6] Fargione J, Hill J, Tilman D, Polasky S, Hawthorne P. Land clearing and the biofuel carbon debt. Science 2008;319:1235-8.

[7] CBES. Land-use change and bioenergy: report from the 2009 workshop. In: U.S. Department of Energy OoEEaREaORNL, Center for Bioenergy Sustainability, editor. Land-use change and bioenergy experts workshop. Vonore, 
Tennessee: Center for BioEnergy Sustainability, Oak Ridge National Laboratory; 2009. p. 76.

[8] Banse M, van Meijl H, Tabeau A, Woltjer G, Hellmann F, Verburg PH. Impact of EU biofuel policies on world agricultural production and land use. Biomass Bioenergy 2011;35:2385-90.

[9] Johansson D, Azar C. A scenario based analysis of land competition between food and bioenergy production in the US. Clim Change 2007;82:267-91.

[10] Keeney R, Hertel TW. The indirect land use impacts of U.S. biofuel policies: the importance of acreage, yield, and bilateral trade responses. GTAP working paper. West Lafayette IN: Center for Global Trade Analysis, Department of Agricultural Economics, Purdue University; 2008. p. 38.

[11] Kim H, Kim S, Dale BE. Biofuels land use change and greenhouse gas emissions: some unexplored variables. Environ Sci Technol 2009;43:961-7.

[12] Lapola DM, Schaldach R, Alcamo J, Bondeau A, Koch J, Koelking C, et al. Indirect land-use changes can overcome carbon savings from biofuels in Brazil. Proc Nat Acad Sci USA 2010;107:3388-93.

[13] Melillo JM, Reilly JM, Kicklighter DW, Gurgel AC, Cronin TW, Paltsev S, et al. Indirect emissions from biofuels: how important? Science 2009;326:1397-9.

[14] Searchinger T, Heimlich R, Houghton RA, Dong F, Elobeid A, Fabiosa J, et al Use of U.S. croplands for biofuels increases greenhouse gases through emissions from land-use change. Science 2008;319:1238-40.

[15] Righelato R, Spracklen DV. Carbon mitigation by biofuels or by saving and restoring forests? Science 2007;317:902.

[16] Ridley CE, Clark CM, LeDuc SD, Bierwagen BG, Lin BB, Mehl A, et al. Biofuels: network analysis of the literature reveals key environmental and economic unknowns. Environ Sci Technol 2012;46:1309-15.

[17] Edwards R, Mulligan D, Marelli L. Indirect land use change from increased biofuels demand-comparison of models and results for marginal biofuels production from different feedstocks. (JRC scientific and technical reports). Ispra (VA), Italy: European Commission, Joint Research Centre, Institute for Energy; 2010

[18] Witcover J, Yeh S, Sperling D. Policy options to address global land use change from biofuels. Energy Policy 2013;56:63-74.

[19] Finkbeiner M. Indirect land use change-help beyond the hype? Biomass Bioenergy 2014;62:218-21.

[20] Khanna M, Crago CL. Measuring indirect land use change with biofuels: implications for policy. Annu Rev Resour Econ 2012;4:161-84.

[21] Di Lucia L, Ahlgren S, Ericsson K. The dilemma of indirect land-use changes in EU biofuel policy-an empirical study of policy-making in the context of scientific uncertainty. Environ Sci Policy 2012;16:9-19.

[22] Nassar AM, Harfuch L, Bachion LC, Moreira MR. Biofuels and land-use changes: searching for the top model. Interface Focus 2011;1:224-32.

[23] Warner E, Inman D, Kunstman B, Bush B, Vimmerstedt L, Peterson S, et al. Modeling biofuel expansion effects on land use change dynamics. Environ Res Lett 2013;8:015003.

[24] Kim S, Dale BE. Indirect land use change for biofuels: testing predictions and improving analytical methodologies. Biomass Bioenergy 2011;35:3235-40.

[25] Hertel TW, Tsigas ME. Chapter 2: "structure of GTAP". In: Hertel TW, editor: Global trade analysis: modeling and applications. Cambridge: Cambridge University Press; 1997.

[26] Demirbas A. Political, economic and environmental impacts of biofuels: a review. Appl Energy 2009;86:108-17.

[27] Gnansounou E, Panichelli L. Background document. Workshop on biofuels and land use change. São Paulo, Brazil: Roundtable on Sustainable Biofuels, Energy Center, EPFL; 2008.

[28] van Tongeren F, van Meijl H, Veenendal P, Frandsen S, Staehr M, Brockmeier M, et al. In: Review of agricultural trade models: an assessment of models with EU policy relevance third annual conference on global economic analysis. Monash University, Australia: GTAP; 2002.

[29] Witzke P, Banse M, Gömann H, Heckelei T, Breuer T, Mann S, et al. Modelling of energy-crops in agricultural sector models-a review of existing methodologies. In: Domínguez Ignacio Pérez, Müller Marc, editors. JRC scientific and technical reports. Luxembourg: European Commission, Joint Research Centre, Institute for Prospective Technological Studies; 2008. p. 59.

[30] De La Torre Ugarte D, English B, Jensen K, Hellwinckel C, Menard J, Wilson B. Economic and agricultural impacts of ethanol and biodiesel expansion. Knoxville, TN, US: Department of Agricultural Economics-The University of Tennessee; 2006; 98.

[31] De La Torre Ugarte DG, Ray DE. Biomass and bioenergy applications of the POLYSYS modeling framework. Biomass Bioenergy 2000;18:291-308.

[32] Havlík P, Schneider UA, Schmid E, Böttcher H, Fritz S, Skalský R, et al. Global land-use implications of first and second generation biofuel targets. Energy Policy 2011;39:5690-702.

[33] Briassoulis H. Analysis of land use change: theoretical and modeling approaches. Lesvos: Regional Research Institute (WVU); 2000.

[34] Lesschen JP, Verburg PH, Staal SJ. Statistical methods for analysing the spatial dimension of changes in land use and farming systems. (LUCC report series no. 7). Nairobi: The International Livestock Research Institute, Nairobi, Kenya- LUCC Focus 3 Office, Wageningen University, the Netherlands; $2005 ; 81$.

[35] Stratus Consulting Inc.. A review of land use/land cover and agricultural change models. (PIER project report). California Energy Commission, Public Interest Energy Research Program; 2005.

[36] Hellmann F, Verburg PH. Spatially explicit modelling of biofuel crops in Europe. Biomass Bioenergy 2011;35:2411-24.
[37] Ronneberger KE. The global agricultural land-use model KLUM-a coupling tool for integrated assessment, PhD thesis. Hamburg: Department Geowissenschaften-Universitat Hamburg; 2006.

[38] Schaldach R, Priess JA, Alcamo J. Simulating the impact of biofuel development on country-wide land-use change in India. Biomass Bioenergy 2011;35:2401-10.

[39] Scheffran J, BenDor T. Bioenergy and land use: a spatial-agent dynamic model of energy crop production in Illinois. Int J Environ Pollut 2009;39: $4-27$.

[40] van Meijl H, van Rheenen T, Tabeau A, Eickhout B. The impact of different policy environments on agricultural land use in Europe. Agric Ecosyst Environ 2006;114:21-38.

[41] Ronneberger K, Berrittellac M, Bosellod F, Tol RSJ. KLUM@GTAP: introducing biophysical aspects of land-use decisions into a general equilibrium model: a coupling experiment. Hamburg: Forschungsstelle Nachhaltige Umweltentwicklung, Universität Hamburg; 2006; 39.

[42] Wu W, Shibasaki R, Yang P, Tan G, Matsumura K-i, Sugimoto K. Global-scale modelling of future changes in sown areas of major crops. Ecol Modell 2007:208:378-90.

[43] Parker DC, Manson SM, Janssen MA, Hoffmann MJ, Deadman P. Multi-agent systems for the simulation of land-use and land-cover change: a review. Ann Assoc Am Geogr 2002:75.

[44] Mathews JA, Goldsztein H. Capturing latecomer advantages in the adoption of biofuels: the case of Argentina. Energy Policy 2009;37:326-37.

[45] Bao Le Q, Park SJ, PLG Vlek, Cremers AB. Land-use dynamic simulator (LUDAS): a multi-agent system model for simulating spatio-temporal dynamics of coupled human-landscape system. I. Structure and theoretical specification. Ecol Inf 2008;3:135-53.

[46] Happe K, Balmann A, Kellermann K. The agricultural policy simulator (Agripolis)-an agent-based model to study structural change in agriculture (version 1.0). Halle: Institute of Agricultural Development in Central and Eastern Europe; 2004; 48.

[47] Bantz SG, Deaton ML. Understanding U.S. biodiesel industry growth using system dynamics modeling. In: DeVore MD, editor. Systems and information engineering design symposium. Harlottesville, VG; 2006

[48] Bush B, Duffy M, Sandor D, Peterson S. Using system dynamics to model the transition to biofuels in the United States. In: International conference on system of systems engineering (SoSE '08). Montreal: IEEE; 2008. p. 1-6.

[49] Franco C, Ochoa MC, Florez AM. A system dynamics approach to biofuels in Colombia. In: International conference of the system dynamics society Albuquerque, New Mexico, US: System Dynamics Society; 2009.

[50] He C, Shi P, Chen J, Li X, Pan Y, Li J, et al. Developing land use scenario dynamics model by the integration of system dynamics model and cellular automata model. Sci China, Ser D: Earth Sci 2005;48:1979-89.

[51] Stamboulis Y, Papachristos G. Investigation and modelling framework of biofuels as a new socio-technical regime. In: International conference of the system dynamics society. Athens, Greece; 2008.

[52] Jahara Y, Sabri A, Kennedy SW. Impacts of biodiesel development on the palm oil industry. Malays J Econ Stud 2006;43:1-13.

[53] Kim GR. Analysis of global food market and food-energy price links-based on system dynamics approach. In: International conference of the system dynamics society. Albuquerque, New Mexico, US: System Dynamics Society: 2009.

[54] Sandvik S, Moxnes E. Peak oil, biofuels, and long-term food security. In: International conference of the system dynamics society. Albuquerque, New Mexico, US: System Dynamics Society; 2009.

[55] Shri Dewi A, Fatimah MA, Mad NS, Zulkornain Y. The impact of biodiesel demand on the Malaysian palm oil market: a combination of econometric and system dynamics approach. In: International conference on business and economic research (ICBER). Kuching, Sarawak: Global Research Agency 2010.

[56] Saeed K. Agricultural land use and food security in Asia: green revolution and beyond. Social science and policy studies. Worcester, MA: Worcester Polytechnic Institute; 2000; 24.

[57] Shen Q, Chen Q, Tang B-s, Yeung S, Hu Y, Cheung G. A system dynamics model for the sustainable land use planning and development. Habitat Int 2009:33:15-25.

[58] Yamamoto H, Fujino J, Yamaji K. Evaluation of bioenergy potential with a multi-regional global-land-use-and-energy model. Biomass Bioenergy 2001;21:185-203.

[59] Yamamoto H, Yamaji K, Fujino J. Evaluation of bioenergy resources with a global land use and energy model formulated with SD technique. Appl Energy 1999;63:101-13.

[60] Sheehan JJ. Sustainable biofuels: a commonsense perspective on California's approach to biofuels \& global land use. Ind Biotechnol 2009:93-103.

[61] Monson M. Minnesota biofuels policy: analysis of the existing renewable fue standard and a potential low carbon fuel standard. In: International conference of the system dynamics society. Athens, Greece: System Dynamics Society; 2008.

[62] Szarka N, Kakucs O, Wolfbauer J, Bezama A. Atmospheric emissions modeling of energetic biomass alternatives using system dynamics approach. Atmos Environ 2008;42:403-14.

[63] Yamamoto H, Yamaji K, Fujino J. Scenario analysis of bioenergy resources and $\mathrm{CO}_{2}$ emissions with a global land use and energy model. Appl Energy 2000;66:325-37. 
[64] Brander M, Tipper R, Hutchison C, Davis G. Consequential and attributional approaches to LCA: a guide to policy makers with specific reference to greenhouse gas LCA of biofuels. Edinburgh, UK: Ecometrica; 2009; 14.

[65] Baitz M, Kreissig J, Wolf M. Method for integrating land use into life-cycleassessment (LCA). Forstwiss Centralbl 2000;119:128-49.

[66] Brentrup F, Kusters J, Kuhlmann H, Lammel J. Environmental impact assessment of agricultural production systems using the life cycle assessment methodology: I. Theoretical concept of a LCA method tailored to crop production. Eur J Agron 2004;20:247-64.

[67] Canals LMI, Muller-Wenk R, Bauer C, Depestele J, Dubreuil A, Knuchel RF, et al. Key elements in a framework for land use impact assessment within LCA. Int J Life Cycle Assess 2007:12:2-4.

[68] Gnansounou E, Dauriat A, Villegas J, Panichelli L. Life cycle assessment of biofuels: energy and greenhouse gas balances. Bioresour Technol 2009;100: 4919-30.

[69] Larson ED. A review of life-cycle analysis studies on liquid biofuel systems for the transport sector. Energy Sustainable Dev 2006;10:109-26.

[70] Cherubini F. GHG balances of bioenergy systems-overview of key steps in the production chain and methodological concerns. Renewable Energy 2009;35:1565-73.

[71] Malça J, Freire F. Life-cycle studies of biodiesel in Europe: a review addressing the variability of results and modeling issues. Renewable Sustainable Energy Rev 2010;15:338-51.

[72] Sanchez ST, Woods J, Akhurst M, Brander M, O'Hare M, Dawson TP, et al. Accounting for indirect land-use change in the life cycle assessment of biofuel supply chains. J R Soc Interface 2012.

[73] Beach RH, McCarl BA. U.S. agricultural and forestry impacts of the energy independence and security act: FASOM results and model description. Washington, DC: Research Triangle Institute (RTI) International; 2010; 178.

[74] BRDB. Increasing feedstock production for biofuels: economic drivers environmental implications, and the role of research. In: Biomass research and development initiative (BR\&Di), editor.: The Biomass Research and Development Board (BRDB); 2008. p. 197. Available from: 〈http://www usbiomassboard.gov/pdfs/increasing_feedstock_revised.pdf).

[75] Burniaux J-M, Truong TP. GTAP-E: an energy-environmental version of the GTAP model. GTAP technical paper. West Lafayette, IN: Center for Global Trade Analysis, Department of Agricultural Economics, Purdue University 2002. p. 69.

[76] Reilly JM, Paltsev S. Biomass energy and competition for land. GTAP working paper-joint program on the science and policy of global change. Cambridge: Massachusetts Institute of Technology; 2008. p. 23.

[77] Taheripour F, Hertel TW, Tyner WE, Beckman JF, Birur DK. Biofuels and their by-products: global economic and environmental implications. GTAP working paper. West Lafayette IN: Center for Global Trade Analysis, Department of Agricultural Economics, Purdue University; 2008. p. 28

[78] Birur DK, Hertel TW, Tyner WE. Impact of biofuel production on world agricultural markets: a computable general equilibrium analysis. GTAP working paper. West Lafayette IN: Center for Global Trade Analysis, Department of Agricultural Economics, Purdue University; 2008. p. 63.

[79] Alla G, Hertel TW, Rose S, Sohngen B. Biofuels mandates, land use and global greenhouse gas emissions. In: 11th annual conference on global economic analysis. Helsinki, Finland: GTAP; 2008.

[80] Britz W, Hertel TW. Impacts of EU biofuels directives on global markets and EU environmental quality: an integrated PE, global CGE analysis. Agric Ecosyst Environ 2011;142:102-9.

[81] Hertel TW, Tyner WE, Birur DK. Biofuels for all? Understanding the global impacts of multinational mandates. GTAP working paper. West Lafayette IN: Center for Global Trade Analysis, Department of Agricultural Economics, Purdue University; 2008. p. 48.

[82] Tabeau A, Banse M, Woltjer G, van Meijl H. Impact of the EU biofuels directive on the EU food supply chain. In: 113th EAAE seminar "a resilient European food industry and food chain in a challenging world". Chania, Crete, Greece: EAAE; 2009

[83] Banse M, van Meijl H, Tabeau A, Woltjer G, Will EU. biofuel policies affect global agricultural markets? Eur Rev Agric Econ 2008;35:117-41.

[84] EPA. Renewable fuel standard program: (RFS2) regulatory impact analysis. Washington, DC: Assessment and Standards Division, Office of Transportation and Air Quality, U.S. Environmental Protection Agency; 2010; 1107.

[85] Hellmann F, Verburg PH. Impact assessment of the European biofuel directive on land use and biodiversity. J Environ Manage 2010;91:1389-96.

[86] Gurgel A, Reilly JM, Paltsev S. Potential land use implications of a global biofuels industry. J Agric Food Ind Organ 2007:5 (Article 9).

[87] Havlík P, Schneider UA, Schmid E, Böttcher H, Kindermann G, Leduc S, et al. GHG mitigation through bioenergy production versus carbon sinks enhancement: a quantitative analysis. Climate change: global risks, challenges \& decisions. Copenhagen: University of Copenhagen; 2009.

[88] APAC. The POLYSYS modeling framework: a documentation. (Available from). Knoxville, Tennessee: University of Tennesse-Institute of AgricultureAgricultural Policy Analysis Center (APAC); 2012; 169. 〈http://www.agpo licy.org/tools/doccom.pdf

[89] LEI. (Report to the GTAP advisory board). Agricultural Economic Research Institute (LEI)-Wageningen University; 2011; 6.

[90] Banse M, van Meijl H, Tabeau A, Woltjer G. Impact of EU biofuel policies on world agricultural and food markets. The Hague: Agricultural Economics Research Institute (LEI); 2007; 29.
[91] Banse M, van Meijl H, Woltjer G. The impact of first and second generation biofuels on global agricultural production, In: Trade and land use. 11th annual conference on global economic analysis,. Helsinki, Finland: GTAP; 2008

[92] Koplow D. State and federal subsidies to biofuels: magnitude and options for redirection. Int J Biotechnol 2009;11:92-126.

[93] Gecan R, Johansson R. Using biofuel tax credits to achieve energy and environmental policy goals. Congress of the United States-Congressional Budget Office; 2010; 28.

[94] Kutas G, Lindberg C, Steenblik R. Biofuels-at what cost? Government support for ethanol and biodiesel in the European Union. In: OECD, editor: The Global Subsidies Initiative (GSI); 2007. p. 114.

[95] Ignaciuk A, Vohringer F, Ruijs A, van Ierland EC. Competition between biomass and food production in the presence of energy policies: a partial equilibrium analysis. Energy Policy 2006;34:1127-38.

[96] Powell AA, Gruen FHG. The constant elasticity of transformation production frontier and linear supply system. Int Econc Rev 1968;9:315-28.

[97] Darwin R, Tsigas M, Lewandrowski J, Raneses A. Land use and cover in ecological economics. Ecol Econ 1996;17:157-81.

[98] Darwin R. FARM: a global framework for integrated land use/cover modeling. Canberra: CRES, ANU; 1998; 18.

[99] Ronneberger K, Schneider UA, Tol RSJ. KLUM: a simple model of global agricultural land use as a coupling tool of economy and vegetation. Working papers FNU-65 research unit sustainability and global change, Hamburg University; 2005.

[100] Malczynski LA, Ellison J, Taylor RA. Biofuels deployment model for modeling time-evolution of ethanol production in the U.S. In: International conference of the systems dynamics society. Albuquerque, New Mexico, US: Systems Dynamics Society; 2009.

[101] West T, Dunphy-Guzman K, Sun A, Malczynski L, Reichmuth D, Larson R, et al. Feasibility, economics, and environmental impact of producing 90 billion gallons of ethanol per year by 2030. In: White paper, editor. Livermore, CA: Sadia National Laboratories; 2009. p. 30.

[102] Hertel TW, Rose S, Tol RSJ. Land use in computable general equilibrium models: an overview. GTAP working paper GTAP; 2008.

[103] Golub A, Hertel TW, Sohngen B. Land use modeling in recursively-dynamic GTAP framework. GTAP working paper: GTAP; 2008.

[104] van der Mensbrugghe D. LINKAGE technical reference document. Mimeo. Washington, DC: The World Bank; 2005.

[105] Edwards R, Mulligan D, Marelli L. Comparison of models and results for marginal biofuels production from different feedstocks. Indirect land use change from increased biofuels demand. Brussels; 2010.

[106] Al-Riffai P, Dimaranan B, Laborde D. Global trade and environmental impact study of the EU biofuels mandate. (ATLAS Consortium). Washington, DC: IFPRI; 2010.

[107] Braimoh AK, Onishi T. Geostatistical techniques for incorporating spatial correlation into land use change models. Int J Appl Earth Obs Geoinf 2007;9:438-46.

[108] Aguiar APD, Câmara G, Escada MIS. Spatial statistical analysis of land-use determinants in the Brazilian Amazonia: exploring intra-regional heterogeneity. Ecol Modell 2007;209:169-88.

[109] Verburg PH, de Koning GHJ, Kok K, Veldkamp A, Bouma J. A spatial explicit allocation procedure for modelling the pattern of land use change based upon actual land use. Ecol Modell 1999;116:45-61.

[110] Batty M, Xie Y, Sun Z. Modeling urban dynamics through GIS-based cellular automata. Comput Environ Urban Syst 1999;23:205-33.

[111] Pijanowski BC, Brown DG, Shellito BA, Manik GA. Using neural networks and GIS to forecast land use changes: a land transformation model. Comput Environ Urban Syst 2002;26:553-75.

[112] Leeuwen JP, Timmermans HJP, Osaragi T, Aoki Y. A method for estimating land use transition probability using raster data. (Innovations in design \& decision support systems in architecture and urban planning). The Netherlands: Springer; 2006; 69-84.

[113] Vega E, Baldi G, Jobbágy EG, Paruelo J. Land use change patterns in the Río de la Plata grasslands: the influence of phytogeographic and political boundaries. Agric Ecosyst Environ 2009;134:287-92.

[114] de Koning GHJ, Veldkamp A, Fresco LO. Land use in Ecuador: a statistical analysis at different aggregation levels. Agric Ecosyst Environ 1998;70:231-47.

[115] Cardille JA, Foley JA. Agricultural land-use change in Brazilian Amazonia between 1980 and 1995: evidence from integrated satellite and census data. Remote Sens Environ 2003;87:551-62.

[116] de Barros Ferraz SF, Vettorazzi CA, Theobald DM, Ballester MVR. Landscape dynamics of Amazonian deforestation between 1984 and 2002 in central Rondonia, Brazil: assessment and future scenarios. For Ecol Manage 2005;204:69-85.

[117] Kløverpris J, Wenzel H, Banse M, Milà i Canals L, Reenberg A. Conference and workshop on modelling global land use implications in the environmental assessment of biofuels. Int J Life Cycle Assess 2008;13:178-83.

[118] Kløverpris J, Wenzel H, Nielsen P. Life cycle inventory modelling of land use induced by crop consumption: Part 1: Conceptual analysis and methodological proposal. Int J Life Cycle Assess 2008;13:13-21.

[119] Kløverpris JH, Baltzer K, Nielsen P. Life cycle inventory modelling of land use induced by crop consumption: Part 2: Example of wheat consumption in Brazil, China, Denmark and the USA. Int J Life Cycle Assess 2010;15:90-103. 
[120] Frischknecht R, Jungbluth N, Althaus H-J, Doka G, Dones R, Heck T, et al. The ecoinvent database: overview and methodological framework (7 pp). Int J Life Cycle Assess 2005;10:3-9.

[121] Jungbluth N, Faist Emmenegger M, Dinkel F, Stettler O, Doka G, Chudacoff M, et al. Life cycle inventories of bioenergy. Data v20. Uster: Swiss Center for Life Cycle Inventories; 2007; 727.

[122] FAPRI. Documentation of the FAPRI modeling system. In: FAPRI-UMC, editor. Report no. 12-04. Park DeVille Drive, Suite E, Columbia: Food and Agricultural Policy Research Institute; 2004. p. 238.

[123] Winrock. The impact of expanding biofuel production on GHG emissions: accessing and interpreting existing data. Arlington, VA: Winrock International; 2009; 72.

[124] Veldkamp A, Lambin EF. Predicting land-use change. Agric Ecosyst Environ 2001;85:1-6.

[125] Veldkamp A, Fresco LO. CLUE: a conceptual model to study the conversion of land use and its effects. Ecol Modell 1996;85:253-70.

[126] Popp A, Dietrich JP, Lotze-Campen H, Klein D, Bauer N, Krause M, et al. The economic potential of bioenergy for climate change mitigation with special attention given to implications for the land system. Environ Res Lett 2011;6:034017.

[127] Golub A, Hertel TW, Lee H-L, Ramankutty N. Modeling land supply and demand in the long run. In: Ninth annual conference on global economic analysis. Addis Ababa, Ethiopia: Purdue University-McGill University; 2006.

[128] Lee HL, Hertel TW, Sohngen B, Ramankutty N. Towards an integrated land use data base for assessing the potential for greenhouse gas mitigation. GTAP technical paper; 2005.

[129] Ahammad H, Mi R. Land Use Change Modeling in GTEM: Accounting for forest sinks. EMF 22: Climate Change Control Scenarios. Stanford University, California: Australian Bureau of Agricultural and Resource Economics; 2005.

[130] Ahmed SA, Hertel TW, Lubowski R. Calibration of a land cover supply function using transition probabilities. GTAP research memorandum no. 14 West Lafayette, IN, US: Center for Global Trade Analysis, Department of Agricultural Economics, Purdue University; 2008. p. 9.

[131] Kamusoko C, Aniya M, Adi B, Manjoro M. Rural sustainability under threat in Zimbabwe-simulation of future land use/cover changes in the Bindura district based on the Markov-cellular automata model. Appl Geogr 2009;29:435-47.

[132] López E, Bocco G, Mendoza M, Duhau E. Predicting land-cover and land-use change in the urban fringe: a case in Morelia city, Mexico. Landscape Urban Plann 2001;55:271-85.

[133] Ministry of Agriculture. Brazilian bioenergy plan 2006-2011. In: Secretariat for Production and Agroenergy, editor. Brasília DF: Embrapa; 2006. p. 118.

[134] SyCDNA. Ley 26.093: Régimen de Regulación y Promoción para la Producción y Uso Sustentables de Biocombustibles. Buenos Aires: Senado y Cámara de Diputados de la Nación Argentina; 2006. p. 5.

[135] Rossetti MD, Hill RR, Johansson B, Dunkin A, Ingalls RG. An agent-based simulation model for the market diffusion of a second generation biofuel. In: Kiesling E, Gunther M, Stummer C, Wakolbinger LM, editors. 2009 Winter simulation conference. Vienna; 2009.

[136] Fernandez LE. Linking global and local dynamics: modeling indirect land use change from biofuel demand, global climate \& energy project. (Expert workshop on biofuels and land-use change. Sao Paulo, Brazil: Round Table on Sustainable Biofuels (RSB)-CGSE-EPFL). Stanford University; 2008.

[137] Monfreda C, Ramankutty N, Hertel TW. Global agricultural land use data for climate change analysis. GTAP working paper GTAP; 2008.

[138] Lee HL, Hertel TW, Rose S, Avetisyan M. An integrated global land use data base for CGE analysis of climate policy options. GTAP working paper: GTAP; 2008

[139] Barr KJ, Babcock BA, Carriquiry M, Nasser A, Harfuch L. Agricultural land elasticities in the United States and Brazil. In: Working paper 10-WP 505, editor. Ames, Iowa: Center for Agricultural and Rural Development-Iowa State University; 2010.

[140] Carballo S, Hilbert J. Propuesta metodologia para la determinación de zonas aptas para la exportación de biodiesel de soja Argentino. Buenos Aires: INTA Castelar; 2010.
[141] Houghton RA, Hackler JL. Carbon flux to the atmosphere from land-use changes: 1850 to 1990. In: Cushman RM, editor. Carbon dioxide information analysis center - environmental sciences division - Oak Ridge National Laboratory. Massachusetts: The Woods Hole Research Center Woods Hole; 2001. p. 74.

[142] IPCC. Good practice guidance for land-use, land-use change and forestry. IPCC National Greenhouse Gas Inventories Programme: IPCC; 2006.

143] Carré F, Hiederer R, Blujdea V, Koeble R. Background guide for the calculation of land carbon stocks in the biofuels sustainability scheme, drawing on the 2006 IPCC guidelines for national greenhouse gas inventories. In: JRC reference reports, editor. Ispra (VA), Italy: European Commission, Joint Research Centre, Institute for Environment and Sustainability; 2010. p. 128

[144] Hiederer R, Ramos F, Capitani C, Koeble R, Blujdea V, Gomez O, et al Biofuels: a new methodology to estimate GHG emissions from global land use change: a methodology involving spatial allocation of agricultural land demand and estimation of $\mathrm{CO}_{2}$ and $\mathrm{N}_{2} \mathrm{O}$ emissions. (JRC scientific and technical reports). Ispra (VA), Italy: European Commission, Joint Research Centre; 2010.

[145] OECD. Agricultural market impacts of future growth in the production of biofuels. (Working party on agricultural policies and markets). Paris, France: OECD, Directorate for Food, Agriculture and Fisheries, Committee for Agriculture; 2006.

[146] OECD. Biofuel support policies: an economic assessment. Paris, France: OECD; 2008; 146.

[147] Ignaciuk AM, Dellink RB. Biomass and multi-product crops for agricultura and energy production-an AGE analysis. Energy Econ 2006;28:308-25.

[148] Veldkamp A, Verburg PH, Kok K, de Koning GHJ, Priess J, Bergsma AR. The need for scale sensitive approaches in spatially explicit land use change modeling. Environ Model Assess 2001;6:111-21.

[149] Li R, Guan Q, Merchant J. A geospatial modeling framework for assessing biofuels-related land-use and land-cover change. Agric Ecosyst Environ 2012:161:17-26.

[150] Sheehan JJ. Biofuels and the conundrum of sustainability. Curr Opin Biotechnol 2009;20:318-24.

[151] Sterman JD. Business dynamics: systems thinking and modeling for a complex world. Boston: Irwin/McGraw-Hill; 2000.

[152] Beach RH, Adams D, Alig R, Baker J, Latta GS, McCarl BA, et al. Model documentation for the forest and agricultural sector optimization model with greenhouse gases (FASOMGHG). In: US EPA - Environmental Protection Agency - Climate Change Division, editors. Washington, DC: RTI International; 2010. p. 188.

[153] Edmonds J, Wise M, Pitcher H, Richels R, Wigley T, Maccracken C. An integrated assessment of climate change and the accelerated introduction of advanced energy technologies. Mitig Adapt Strateg Global Change 1997;1:311-39.

[154] Wise M, Dooley J, Luckow P, Calvin K, Kyle P. Agriculture, land use, energy and carbon emission impacts of global biofuel mandates to mid-century. Appl Energy 2014;114:763-73.

[155] Latta GS, Baker JS, Beach RH, Rose SK, McCarl BA. A multi-sector intertemporal optimization approach to assess the GHG implications of U.S. forest and agricultural biomass electricity expansion. J For Econ 2013;19:361-83.

[156] Woltjer G, Banse M, van Meijl H, Tabeau A. Alternative approaches to extend GTAP to biofuel crops. (In: 10th annual GTAP conference). Indiana, USA: Purdue University; 2007 (GTAP).

[157] Woltjer G, Banse M, van Meijl H, Tabeau A. Biofuels and long-term land use dynamics. (In: GTAP conference). Helsinki, Finland: GTAP; 2008.

[158] Bush B, Inman D, Macknick J, Peterson S. System dynamic approach to model land-use change from biofuels. (National renewable energy laboratory milestone report). Golden, CO: National Renewable Energy Laboratory; 2012.

[159] O'Hare M, Plevin RJ, Martin JI, Jones AD, Kendall A, Hopson E. Proper accounting for time increases crop-based biofuels' greenhouse gas deficit versus petroleum. Environ Res Lett 2009;4:024001.

[160] de Gorter H, Tsur Y. Cost and benefit tests for GHG emissions from biofuel production. Eur Rev Agric Econ 2010;37:133-45. 